\title{
IL-6 triggers malignant features in mammospheres from human ductal breast carcinoma and normal mammary gland
}

\author{
Pasquale Sansone,,1,2 Gianluca Storci,1,3 Simona Tavolari,4 Tiziana Guarnieri, ${ }^{4}$ Catia Giovannini,1,5 \\ Mario Taffurelli, ${ }^{6}$ Claudio Ceccarelli, ${ }^{1,7}$ Donatella Santini, ${ }^{7}$ Paola Paterini, ${ }^{4}$ Kenneth B. Marcu, ${ }^{1,8}$ \\ Pasquale Chieco, ${ }^{1}$ and Massimiliano Bonafè̀ ${ }^{1,3}$

\begin{abstract}
${ }^{1}$ Center for Applied Biomedical Research, St. Orsola-Malpighi University Hospital, ${ }^{2}$ Department of Pharmacology and Toxicology, ${ }^{3}$ Department of Experimental Pathology, ${ }^{4}$ Department of Experimental Evolutionary Biology, ${ }^{5}$ Department of Internal Medicine and Gastroenterology, ${ }^{6}$ Department of Surgical and Anesthesiological Sciences, and ${ }^{7}$ Department of Radiological and Histopathological Sciences, University of Bologna, Bologna, Italy. ${ }^{8}$ Biochemistry Department, Stony Brook University, Stony Brook, New York, USA.
\end{abstract}

\begin{abstract}
High serum levels of IL- 6 correlate with poor outcome in breast cancer patients. However, no data are available on the relationship between IL-6 and mammary stem/progenitor cells, which may fuel the genesis of breast cancer in vivo. Herein, we address this issue in the MCF-7 breast cancer cell line and in primary human mammospheres (MS), multicellular structures enriched in stem/progenitor cells of the mammary gland. MS from node invasive breast carcinoma tissues expressed IL-6 mRNA at higher levels than did MS from matched nonneoplastic mammary glands. In addition, IL-6 mRNA was detected only in basal-like breast carcinoma tissues, an aggressive breast carcinoma variant showing stem cell features. IL-6 treatment triggered Notch-3-dependent upregulation of the Notch ligand Jagged-1 and promotion of MS and MCF-7-derived spheroid growth. Moreover, IL-6 induced Notch-3-dependent upregulation of the carbonic anhydrase IX gene and promoted a hypoxia-resistant/invasive phenotype in MCF-7 cells and MS. Finally, autocrine IL-6 signaling relied upon Notch-3 activity to sustain the aggressive features of MCF-7-derived hypoxia-selected cells. In conclusion, these data support the hypothesis that IL-6 induces malignant features in Notch-3-expressing stem/progenitor cells from human ductal breast carcinoma and normal mammary gland.
\end{abstract}

\section{Introduction}

IL-6, a major mediator of the inflammatory response, plays a primary role in the pathophysiology of cancer $(1,2)$. In breast cancer patients, the extent of the increase in serum IL- 6 correlates with poor disease outcome and reduced prognosis $(3,4)$. Although it has been argued that the cytokine may be secreted by cancer cells, the source of the IL- 6 in cancer patients has not yet been determined $(5,6)$. Cancer cells that are exposed to IL- 6 or secrete the cytokine as an autocrine factor show malignant features, such as enhanced capacity to invade the extracellular matrix and increased drug resistance (7-10). Accordingly, the inactivation of the gp130 protein, which transduces the signaling of IL-6-type cytokines, has been found to reduce the aggressiveness of breast cancer cells in vivo (11). On the basis of these data, the inhibition of the IL-6/IL-6 receptor interaction with specific antibodies has been proposed as a support cancer therapy (12).

Breast cancer has been proposed as a stem cell disease (13). This hypothesis entails the notion that the growth of the tumor mass relies on the proliferation and self-renewal capacity of a small population of cancer-initiating cells known as cancer stem cells (13-16). Moreover, this notion helps elucidate why the dysregulation of stem cell regulatory pathways plays a causative role in breast

Nonstandard abbreviations used: CA-IX, carbonic anhydrase IX; CK, cytokeratin; DFX, desferoxamine; ER, estrogen receptor; IHC, immunohistochemistry; MCF-7(S), MCF-7-derived spheroid(s); MS, mammosphere(s); N-MS, normal MS; pNICD3, pCDNA3.1 vector encoding Notch-3 intracellular active cleaved fragment; shRNA, short hairpin RNA; T-MS, tumor MS

Conflict of interest: The authors have declared that no conflict of interest exists. Citation for this article: J. Clin. Invest. 117:3988-4002 (2007). doi:10.1172/JCI32533. cancer (15). In this regard, transgenic mice overexpressing isoforms of Notch, a signaling pathway active in stem cells, are more prone to develop mammary tumors (17). Further, high levels of Notch isoforms have been found to correlate with a poorer prognostic profile and reduced survival in breast cancer patients $(18,19)$.

Stem/progenitor cells of the mammary gland reside in the basal cell layer (20) and can be expanded in vitro from normal tissues as multicellular spheroids named mammospheres (MS) (21). Prior findings indicate that multicellular MS structures have a clonal origin and have the capacity to reform in vitro after trypsin dissociation. (21). Bilineage (luminal and myoepithelial) progenitors are enriched up to 8 times in MS compared with freshly isolated human mammary cells and constitute virtually $100 \%$ of the cells in secondary MS $(21,22)$. MS regenerate and also form tubuloalveolar structures in matrigel and in immunodeficient mice cleared of fat pads (21-24). Similarly, MS from breast cancer tissues have been shown to proliferate in vitro and also generate tubuloalveolar structures composed of CD $44^{+} \mathrm{CD} 24^{-}$cells (25-27). Interestingly, the $\mathrm{CD} 44^{+} \mathrm{CD} 24^{-}$cell population has been shown to be extremely enriched in putative breast cancer stem cells (28).

Both normal and tumor MS (N-MS and T-MS, respectively) have been shown to require active Notch signaling to sustain their survival and proliferation capacity (24-26). Moreover, MS express gp130 and are potential targets of IL-6-type cytokines (21).

Here, we provide evidence that IL- 6 gene expression is upregulated in MS obtained from aggressive ductal breast carcinomas and that IL-6 regulates a Notch-3-dependent signaling pathway that promotes self renewal, hypoxia survival, and the invasive potentials of N-MS and T-MS. 


\section{Table 1}

Clinical-pathologic parameters of 17 breast ductal carcinomas used for T-MS and N-MS generation

\begin{tabular}{lcccccccccc}
\multicolumn{2}{c}{ SampleAge (yr)pT } & pN & G & NG & ER & HER-2 & EGFR & T-MS & N-MS \\
$1^{A}$ & 55 & 1 & 0 & 2 & 2 & + & 0 & - & $\mathrm{Y}$ & NA \\
$2^{A}$ & 82 & 2 & 1 & 2 & 3 & + & 0 & - & $\mathrm{Y}$ & $\mathrm{NA}$ \\
$3^{\mathrm{A}}$ & 61 & 2 & 1 & 2 & 2 & - & 2 & - & $\mathrm{Y}$ & $\mathrm{NA}$ \\
4 & 46 & 1 & 1 & 2 & 2 & + & 1 & - & $\mathrm{Y}$ & $\mathrm{Y}$ \\
5 & 73 & 2 & 3 & 2 & 2 & + & 0 & - & $\mathrm{Y}$ & $\mathrm{Y}$ \\
6 & 62 & 1 & 3 & 3 & 3 & + & 2 & - & $\mathrm{Y}$ & $\mathrm{Y}$ \\
7 & 58 & 1 & 0 & 3 & 3 & + & 1 & - & $\mathrm{N}$ & $\mathrm{Y}$ \\
8 & 83 & 1 & 3 & 2 & 3 & + & 3 & - & $\mathrm{Y}$ & $\mathrm{Y}$ \\
9 & 63 & 2 & 2 & 3 & 3 & - & 3 & - & $\mathrm{Y}$ & $\mathrm{Y}$ \\
10 & 55 & 1 & 0 & 3 & 3 & + & 3 & - & $\mathrm{N}$ & $\mathrm{Y}$ \\
11 & 59 & 1 & 0 & 3 & 3 & + & 1 & - & $\mathrm{Y}$ & $\mathrm{Y}$ \\
12 & 44 & 1 & 0 & 1 & 2 & + & 0 & - & $\mathrm{Y}$ & $\mathrm{Y}$ \\
13 & 59 & 1 & 1 & 2 & 2 & + & 1 & - & $\mathrm{N}$ & $\mathrm{Y}$ \\
14 & 39 & 2 & 3 & 2 & 3 & + & 1 & - & $\mathrm{Y}$ & $\mathrm{Y}$ \\
15 & 73 & 1 & 1 & 2 & 3 & + & 1 & - & $\mathrm{Y}$ & $\mathrm{Y}$ \\
16 & 85 & 2 & 1 & 3 & 3 & - & 0 & - & $\mathrm{N}$ & $\mathrm{Y}$ \\
17 & 61 & 2 & 1 & 2 & 3 & + & 1 & - & $\mathrm{Y}$ & $\mathrm{Y}$
\end{tabular}

pT, tumor size; $\mathrm{pN}$, nodal involvement; $\mathrm{G}$, grading; NG, nuclear grading; HER-2: ErbB-2 receptor; Y, yes; NA, not available; N, no. AmRNA from the tumor tissue was available.

\section{Results}

High levels of IL-6 $\mathrm{mRNA}$ are present in MS from aggressive ductal breast carcinoma and in basal-like breast carcinoma tissues. T-MS were generated from the tumor tissues of 3 patients with ductal breast carcinoma (samples 1-3; Table 1 and Figure 1A).

T-MS were characterized by immunohistochemistry (IHC). We found that T-MS were composed almost entirely of cells that were CD $44^{+}(97 \% \pm 3 \%)$ and CD24- $(<1 \%$ CD24+; Supplemental Figure 1; supplemental material available online with this article; doi:10.1172/JCI32533DS1), suggesting that the majority of cells in T-MS present a CD44 ${ }^{+} \mathrm{CD} 24^{-}$cancer stem cell phenotype (28). Further, cells in T-MS expressed Oct-4 (88\% $\pm 7 \%)$, which has been previously reported to hyperexpress T-MS (27), and cytokeratin 5 (CK-5; 22\% $\pm 7 \%$ ), which identifies the mammary gland basal cell compartment (ref. 20 and Supplemental Figure 1). IHC showed also that T-MS were composed of E-cadherin ${ }^{+}(97 \% \pm 2 \%)$, CK- $14^{+}$ $(99 \% \pm 1 \%)$, and CK-18 ${ }^{+}(24 \% \pm 7 \%)$ cells, revealing that T-MS are composed of epithelial cells showing ductal (CK-18) and luminal (CK-14) markers (Supplemental Figure 2).

RT-PCR analysis revealed that T-MS, but not the tumor tissues from which T-MS were obtained, expressed detectable levels of IL-6 mRNA (Figure 1B). RT-PCR analysis also revealed that, compared with tumor tissues, T-MS expressed high levels of Bmi-1 mRNA, a gene associated with stem cell renewal (23); CD44 mRNA, a gene whose expression has been associated with cancer stem cell phenotype in different organs $(28,29)$; and CK-5 and Oct-4 mRNA (Figure 1B).

T-MS were then obtained from a set of samples $(n=14)$ in which the normal mammary gland tissue was also available to generate N-MS (Table 1, samples 4-17).

Similar to T-MS, N-MS lacked CD24 expression and contained cells expressing CD44 (95\% $\pm 3 \%)$, CK-5 (14\% $\pm 3 \%)$, CK-14 $(78 \% \pm 7 \%)$, and CK-18 (75\% $\pm 9 \%$; Supplemental Figure 3$)$. The availability of N-MS and T-MS from the same patient allowed us to assess the level of IL- 6 mRNA, accounting for variability caused by genetic makeup and age (30). We found that, compared with matched N-MS, T-MS from node-invasive tumors (pN3/pN2) expressed increased levels of IL-6 mRNA (Figure $1 \mathrm{C})$. The same comparison performed on T-MS generated from scarcely node-invasive tumors ( $\mathrm{pN0} / \mathrm{pN} 1)$ of ductal carcinomas revealed a negligible difference in IL-6 mRNA level between N-MS and T-MS (Figure 1C). Notably, compared with matched N-MS, T-MS obtained from patients affected by $\mathrm{pN} 3 / \mathrm{pN} 2$ invasive tumors expressed similar levels of Bmi-1 and CK-5 mRNA and lower levels of breast cancer resistance protein 1 (BCRP-1) and CD133 mRNA, 2 antigens that have been previously associated with (cancer) stem cell phenotype (refs. 31-33; Figure 1C). The higher level of CD133 expression in N-MS compared with T-MS was also evident in IHC analysis (Supplemental Figure 4A).

We then assessed IL- 6 mRNA in a set of archival breast tumor samples (Table 2), including ductal $(n=10)$ and basal-like $(n=6)$ breast carcinomas, a subtype of cancer showing stem cell features (34-37). This tumor type, similar to MS, was characterized by the expression of CK-5, CK-14, and EGFR protein as well as Bmi-1 and CD133 mRNA (Supplemental Figure 4, $\mathrm{B}$ and $\mathrm{C}$ ), thereby reinforcing the notion of a tight similarity between MS and basal-like breast carcinoma cells (37).

In keeping with this reasoning, we detected IL-6 mRNA in basal-like breast carcinoma tissues, but not in ductal breast carcinoma (Figure 1D). These data indicate that IL- 6 expression occurs in MS obtained from aggressive ductal breast carcinoma and in basal-like breast carcinoma tissues, wherein stem cell-like phenotypes are particularly apparent.

IL-6 promotes MS selfrenewal and MCF-7-derived spheroid formation. To assess the functional role of IL-6 expression in MS, we exposed secondary T-MS to a mAb that blocks the IL- 6 receptor/ligand interaction (anti-IL-6; $1.5 \mu \mathrm{g} / \mathrm{ml}$ ). Exposure of T-MS to anti-IL-6 substantially blunted their secondary regeneration capacity, a functional property that has been referred to as MS self-renewal capability (refs. 21, 22, 25; Figure 2A). Accordingly, we observed that administration of IL-6 $(10 \mathrm{ng} / \mathrm{ml})$ to N-MS and T-MS from the same patient yielded an increase in secondary MS formation compared with MS not exposed to the cytokine, a phenomenon that was hampered by the simultaneous addition of anti-IL-6 $(1.5 \mu \mathrm{g} / \mathrm{ml}$; Figure $2 \mathrm{~B})$. We further investigated this phenomenon in the context of MCF-7-derived spheroids [MCF-7(S)], which have been recently shown to contain a substantial proportion of CD 44+CD24- cells (38). MCF-7(S) expressed high levels of IL-6 mRNA, whereas the mRNA of the cytokine was absent in MCF-7 cells cultured in standard conditions (Figure 2C). Moreover, the administration of anti-IL-6 $(1.5 \mu \mathrm{g} / \mathrm{ml})$ caused a substantial reduction in MCF-7(S) size (Figure 2C). These data indicate that IL-6 mRNA expression promotes growth in suspension and that both autocrine and exogenous IL- 6 promotes MS self renewal.

The MCF-7(S) growth-promoting activity of IL-6 requires Notch-3 gene. Notch genes play a pivotal role in MS self renewal (24-26). In particular, Notch-3 is highly expressed in N-MS and T-MS $(21,26)$, and its blockage induces a marked reduction in MS self renewal and survival (26). On these bases, we tested the hypothesis that the effect of IL- 6 on MS self renewal and MCF-7(S) formation may depend upon Notch-3 gene expression. We found that administration of anti-IL-6 $(1.5 \mu \mathrm{g} / \mathrm{ml})$ to T-MS for 24 hours yielded downregulation in the level of Notch-3 mRNA and that administration 
A

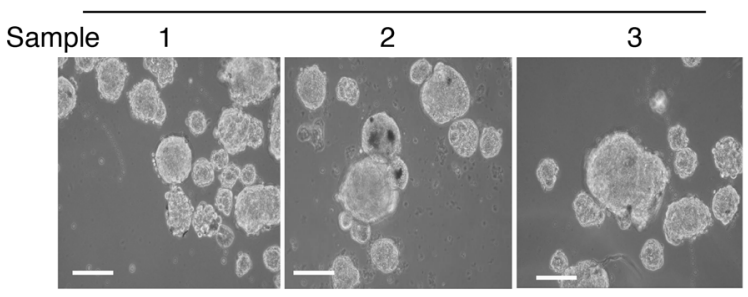

C

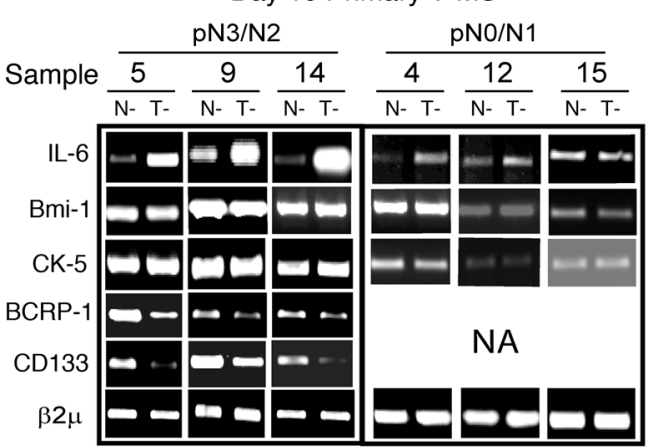

B Day 10 Primary T-MS

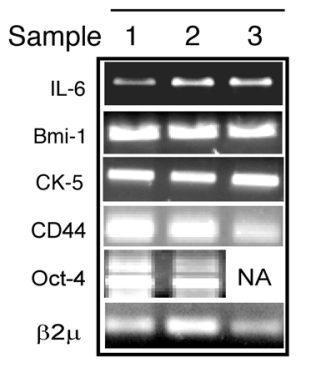

Breast carcinoma

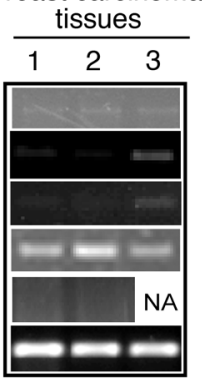

Day 10 Primary T-MS

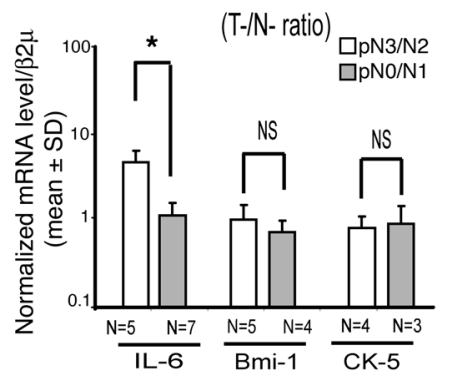

D

Breast carcinoma tissues RT-PCR analysis

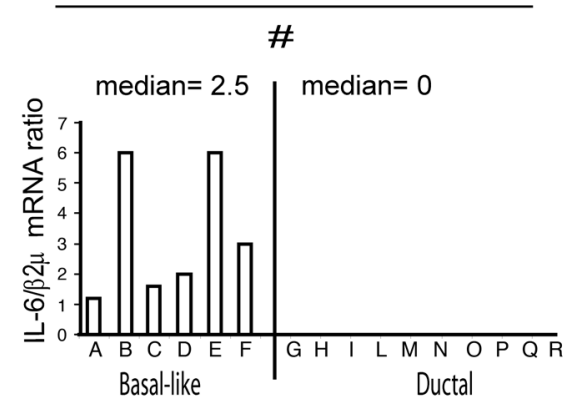

Figure 1

IL-6 mRNA is expressed in MS and in basal-like breast carcinoma tissues. (A) Phase-contrast microscopy of day 10 primary T-MS generated from samples listed in Table 1. Scale bars: $100 \mu \mathrm{m}$. (B) RT-PCR analysis of IL-6, Bmi-1, CK-5, CD44, Oct-4, and $\beta_{2} \mu$ mRNA in T-MS and in tumor tissues from which T-MS had been obtained. (C) Day 10 primary N-MS and T-MS were obtained from the same patient (see Table 1). RT-PCR analysis of IL-6, Bmi-1, CK-5, BCRP-1, and CD133 and quantitation of IL-6, Bmi-1, and CK-5 mRNA, first normalized onto $\beta_{2} \mu$ mRNA and then expressed as a ratio of N-MS to T-MS. ${ }^{*} P=0.031$, Mann-Whitney test. NA, not available. (D) Breast carcinoma tissues from patients affected by basal-like or ductal breast carcinoma (see Table 2) were subjected to RT-PCR analysis. Shown is the ratio of IL-6 to $\beta_{2} \mu$ mRNA. $\# P=0.001$, Mann-Whitney test.

of IL-6 (10 ng/ml) to N-MS for 24 hours elicited upregulation of Notch-3 mRNA (Figure 3A). A similar regulation was observed in MCF-7 cells and MCF-7(S) exposed to IL-6 (10 ng/ml for 24 hours) and in MCF-7(S) exposed to anti-IL-6 $(1.5 \mu \mathrm{g} / \mathrm{ml}$ for 24 hours; Figure $3 \mathrm{~B})$. To better characterize the role of IL-6/Notch-3 interplay in substrate-independent growth, we generated MCF-7(S) using MCF-7 cells stably transduced with a retroviral vector expressing Notch-3-specific (shNotch-3) or control short hairpin RNA (shRNA). We found that MCF-7(S) obtained from control shRNAtransduced MCF-7 cells and generated in the presence of IL-6 (10 $\mathrm{ng} / \mathrm{ml}$ ) showed an increase in size, whereas shNotch-3 MCF-7 cells did not produce MCF-7(S), even in presence of exogenous IL-6 (10 $\mathrm{ng} / \mathrm{ml}$; Figure $3 \mathrm{C}$ ). These data indicate that Notch-3 signaling is of pivotal importance to sustain the IL-6-dependent growth of breast cancer cells in suspension culture.

IL-6 elicits a Notch-3-dependent upregulation of Jagged-1 $m R N A$ expression, which sustains MCF-7(S) formation and promotes MS self renewal. We recently reported that Notch-3 promotes MS survival by interacting with its ligand Jagged-1 (26). Therefore we next evaluated whether Jagged-1 was involved in Notch-3-dependent MS growth. Indeed, either exposing N-MS to IL-6 $(10 \mathrm{ng} / \mathrm{ml})$ or adding antiIL-6 $(1.5 \mu \mathrm{g} / \mathrm{ml})$ to T-MS modulated the expression of Jagged-1 mRNA (Figure 4A). Moreover, we found that in MCF-7 cells, IL-6 elicited upregulation of Jagged-1 mRNA, which was blocked by the coadministration of IL- 6 with the MEK/ERK inhibitor UO-126 (Figure 4B). Furthermore, we found that the upregulation of Jag- ged- 1 induced by IL- 6 was negligible in shNotch-3 MCF-7 cells and that the transfection of pCDNA3.1 vector encoding Notch-3 intracellular active cleaved fragment (pNICD3) into MCF-7 cells triggered an upregulation of Jagged-1 mRNA, which was prevented by the concurrent administration of UO-126 (Figure 4B). In addition, we observed that MCF-7(S) formation was extremely reduced when MCF-7 cells were transfected with a Jagged-1 specific siRNA compared with scrambled control siRNA (Figure 4C). Finally, we observed that an antibody blocking Jagged-1/Notch-3 interaction reduced MS regeneration capacity (Figure 4D), indicating that the Notch-3/Jagged-1 pathway is functionally relevant for IL-6-induced MS formation. Notably, we also found that basal-like breast carcinoma tissues expressed higher Jagged-1 and Notch-3 mRNA levels than did ductal breast carcinoma tissues (Figure 4E). These data suggest that upregulation of Jagged-1 via Notch-3 signaling is crucial for the growth in suspension of breast cancer cells and MS and that this phenomenon may also occur in basal-like breast cancer tissues.

IL-6 induces a Notch-3-dependent upregulation of carbonic anbydrase IX. ERK upregulation has recently been found to enhance the expression of the hypoxia survival gene carbonic anhydrase IX (CA-IX; refs. 26,39). Thus given our above observations, we next evaluated whether IL-6 signaling modulates CA-IX gene expression. Indeed, adding IL-6 $(10 \mathrm{ng} / \mathrm{ml})$ to N-MS induced upregulation of CA-IX mRNA (Figure 5A). Increased CA-IX expression was also observed in MCF-7 cells exposed to IL-6 (10 ng/ $\mathrm{ml}$ for 24 hours), whereas 
Table 2

Clinical-pathologic parameters of 16 archival breast carcinoma tissues assessed by RT-PCR

\begin{tabular}{lcccccccccccc} 
Sample & Age (yr) & pT & pN & G & NG & ER & HER-2 & CK-5 & CK-14 & EGFR & Histotype & Basal-like \\
A & 40 & 2 & 0 & 3 & 3 & - & 0 & + & + & + & IDC & Y \\
B & 55 & 3 & 0 & 3 & 3 & - & 0 & + & + & + & IDC & Y \\
C & 71 & 1 & 1 & 3 & 3 & - & 1 & + & + & + & IDC & Y \\
D & 47 & 4 & 0 & 3 & 3 & - & 0 & + & + & + & IDC & Y \\
E & 78 & 1 & 0 & 3 & 3 & - & 1 & + & + & + & IDC & Y \\
F & 65 & 1 & 0 & 3 & 3 & - & 0 & + & - & + & IDC & Y \\
G & 57 & 2 & 1 & 3 & 3 & - & 0 & - & - & - & IDC & N \\
H & 57 & 3 & 1 & 3 & 3 & - & 0 & - & - & - & IDC & N \\
I & 42 & 1 & 0 & 2 & 3 & - & 0 & - & - & - & IDC & N \\
L & 49 & 1 & 1 & 3 & 3 & + & 2 & - & - & - & IDC & N \\
M & 78 & 4 & 3 & 3 & 3 & + & 0 & - & - & - & IDC & N \\
N & 64 & 1 & 0 & 2 & 3 & - & 0 & - & - & - & IDC & N \\
O & 63 & 2 & 1 & 2 & 3 & - & 2 & - & - & - & IDC & $\mathrm{N}$ \\
$\mathrm{P}$ & 63 & 1 & 1 & 3 & 3 & + & 0 & - & - & - & IDC & $\mathrm{N}$ \\
$\mathrm{Q}$ & 60 & 1 & 3 & 3 & 3 & - & 2 & - & - & - & IDC & $\mathrm{N}$ \\
$\mathrm{R}$ & 45 & 2 & 0 & 2 & 2 & - & 2 & - & - & - & IDC & $\mathrm{N}$ \\
\hline
\end{tabular}

pT, tumor size; pN, nodal involvement; G, grade; NG, nuclear grade; HER-2: ErbB-2 receptor; IDC, infiltrating-ductal-breast carcinoma; $\mathrm{Y}$, yes; N, no. Basal-like breast carcinomas were diagnosed as $\mathrm{CK}-5^{+}$ and/or CK-14+, $\mathrm{EGFR}^{+}, \mathrm{ER}^{-}$, and HER-2-negative or -low (0 or 1 ) ductal breast carcinomas $(34,35)$.

and support the similarity between the gene expression profiles of MS and basal-like breast carcinoma tissues.

IL-6 triggers a Notch-3/CA-IX-dependent increase in the invasiveness of $M S$ and MCF-7 cells. The results illustrated in Figure $5 \mathrm{~B}$ pointed out that IL- 6 induces a Notch-3/ERK-mediated upregulation of CA-IX expression in absence of hypoxia. We then investigated the activity of the IL-6/Notch-3/ CA-IX axis in normoxic conditions. We found that exposure to IL- $6(10 \mathrm{ng} / \mathrm{ml})$ enhanced the capacity of MCF-7 cells to invade the extracellular matrix. This increase was negligible in shNotch-3 MCF-7 cells, and it was also substantially reduced when CA-IX, but not scrambled, siRNA was administered to IL-6-exposed MCF-7 cells (Figure 7A). In keeping with these observations, we found that administration of anti-IL-6 $(1.5 \mu \mathrm{g} / \mathrm{ml})$ or transfection of an IL-6specific siRNA or CA-IX siRNA caused

CA-IX gene expression was markedly reduced by the administration of UO-126 (Figure 5B). Similar to what we observed for Jagged-1 (Figure 4B), CA-IX gene expression was inhibited in shNotch-3 MCF-7 cells, but not control MCF-7 cells, exposed to IL-6, while it was enhanced by transfection of the PNICD3 vector but not in the presence of UO-126 (Figure 5B). Because CA-IX is a hypoxia response gene (39), we investigated whether IL-6 plays a role in the hypoxia response. Exposure of MCF-7 cells to hypoxic stimuli (100 $\mu \mathrm{M}$ desferoxamine [DFX] or low oxygen tension, $<0.1 \% \mathrm{O}_{2}$, for 48 hours), as well as the exposure of N-MS and T-MS to $50 \mu \mathrm{M}$ DFX (48 hours), enhanced the expression of IL-6, Notch-3, and CA-IX mRNAs (Figure 5C). Importantly, upon blocking the upregulation of hypoxia-responsive genes with $100 \mu \mathrm{M}$ DFX, the administration of anti-IL-6 $(1.5 \mu \mathrm{g} / \mathrm{ml})$ to MCF-7 cells caused downregulation of Notch-3 and CA-IX mRNA. In addition, CA-IX mRNA was also downregulated in shNotch-3 MCF-7 cells exposed to $100 \mu \mathrm{M}$ DFX compared with control MCF-7 cells (Figure 5D). Taken together, these results indicate the CA-IX gene expression is regulated by the IL-6/Notch-3 pathway in MCF-7 cells and MS.

IL-6/Notch-3/CA-IX axis promotes bypoxia survival in MCF-7 and MS. CA-IX has been found to play a crucial role in hypoxia survival of breast cancer cells and MS (26). In keeping with these data, we observed a substantial increase compared with matched controls in cell death of MCF-7 cells exposed to $100 \mu \mathrm{M}$ DFX in the presence of anti-IL-6 $(1.5 \mu \mathrm{g} / \mathrm{ml})$ or transfected with a CA-IX-specific siRNA (Figure 6A). Furthermore, a higher degree of hypoxiainduced cell death accompanied by downregulation of CA-IX mRNA was observed in shNotch-3 MCF-7 cells compared with control MCF-7 cells (Figure 6A). In line with these results, we found that exposure of T-MS to anti-IL- 6 or anti-N3 $(1.5$ and $1 \mu \mathrm{g} / \mathrm{ml}$, respectively) or transfection with CA-IX siRNA, in the presence of $50 \mu \mathrm{M}$ DFX, increased cell death compared with a matched scrambled siRNA control (Figure 6B). Interestingly, detectable levels of CA-IX mRNA were found only in tissues from basal-like breast carcinoma (Figure 6C). These data indicate that IL-6/Notch-3induced CA-IX gene expression promotes hypoxia survival in MS a substantial decrease in the invasive potential of T-MS compared with scrambled siRNA (Figure 7B). Further, the administration of IL-6 $(10 \mathrm{ng} / \mathrm{ml})$ enhanced the invasive potential of N-MS, yet this phenomenon was blocked by coadministration of anti-N3 $(1.5 \mu \mathrm{g} /$ $\mathrm{ml}$ ) or transfection of CA-IX, but not scrambled, siRNA (Figure 7C). Parallel to these findings, we observed that IL- 6 enhanced the activity of the extracellular matrix-degrading enzyme MMP-2 in control MCF-7 cells and in scrambled siRNA-transfected MCF-7 cells, but not in shNotch-3 MCF-7 cells or in CA-IX siRNA-transfected ones (Figure 7D). These data suggest that the IL-6/Notch-3dependent upregulation of the CA-IX gene enhances the invasive behavior of MCF-7 cells and MS.

Autocrine IL-6 sustains a CA-IX-dependent aggressive phenotype in MCF-7-derived, bypoxia-selected cells. Taken together, these results suggest that the establishment of an autocrine IL-6 loop may engender cancer cells with a substantial growth advantage over their normal counterparts. To explore this idea, we next examined a MCF-7-derived cell population, HYPO-7, which was obtained by selecting parental MCF-7 cells in the presence of $100 \mu \mathrm{M}$ DFX (see Methods). Such cells, cultured for an extensive time period (up to 1 year) in the absence of DFX were found to constitutively express high levels of IL-6, Notch-3, and CA-IX mRNA (Figure $8 A)$. We found that, compared with scrambled siRNA, administration of IL-6 siRNA to HYPO-7 yielded a decrease in Notch-3 and CA-IX mRNA expression, an increase in the susceptibility to DFXinduced cell death, and a reduction in their invasive potential and MMP-2 activity (Figure 8A). In agreement with the data obtained in MCF-7 cells and MS, we found that the administration of CA-IX, but not scrambled, siRNA to HYPO-7 cells recapitulated the phenotypic changes induced by IL-6 siRNA in HYPO-7 cells (Figure 8B). Interestingly, the effects elicited by IL- 6 siRNA were also observed when HYPO-7 cells were exposed to anti-IL-6 $(1.5 \mu \mathrm{g} / \mathrm{ml}$ for 24 hours; data not shown). Of particular importance, however, was the observation that administration of anti-IL-6 $(1.5 \mu \mathrm{g} / \mathrm{ml}$ for 24 hours) caused downregulation of IL-6 mRNA in HYPO-7 cells as well as in MCF-7(S) and T-MS (Figure 8C). These data sug- 
A

anti-IL6

$(1.5 \mu \mathrm{g} / \mathrm{ml})$
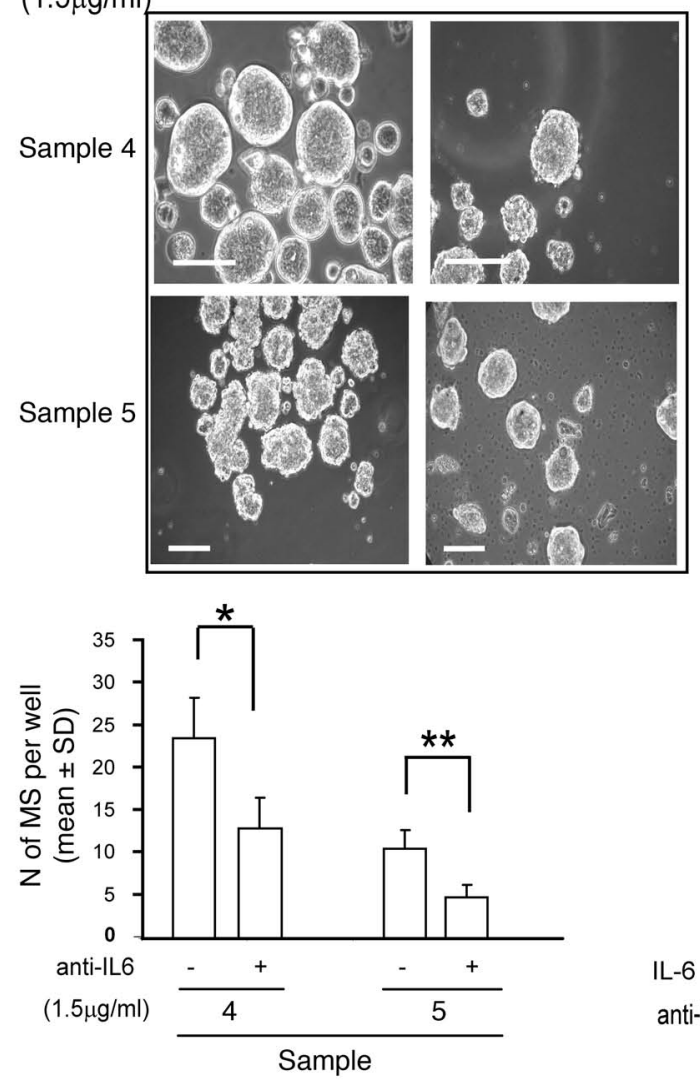

B

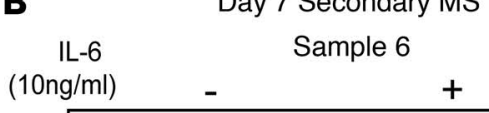

$(10 \mathrm{ng} / \mathrm{m})$
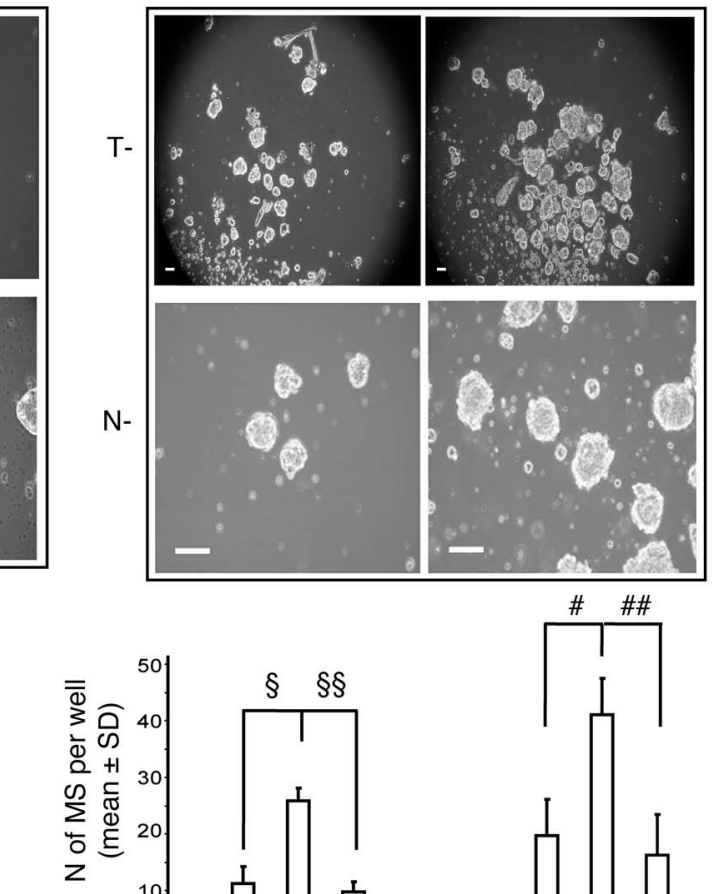

IL-6 (10ng/ml) anti-lL6 $(1.5 \mu \mathrm{g} / \mathrm{ml})$
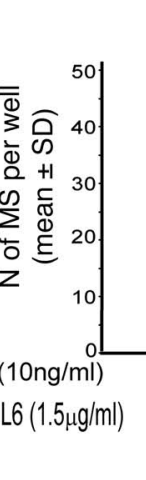

C

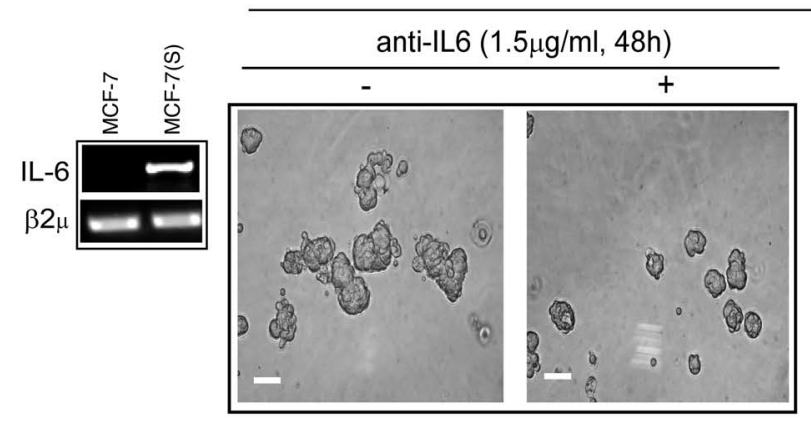

MCF-7(S)

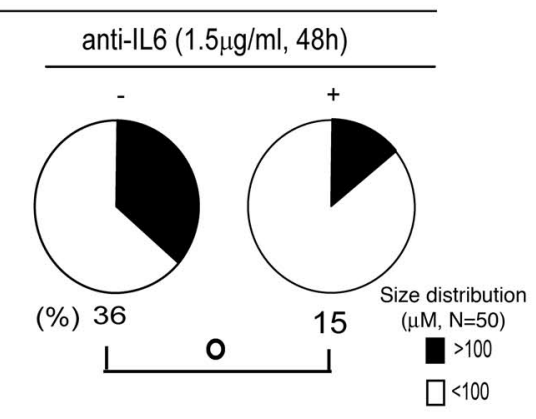

Figure 2

IL-6 sustains MS self renewal and MCF-7 spheroid formation. (A) Day 7 secondary T-MS, generated from primary T-MS in the presence or absence of the mAb anti-IL-6, which blocks the IL-6 receptor/ligand interaction $(1.5 \mu \mathrm{g} / \mathrm{ml})$. Phase-contrast microscopy analysis and number of MS per well $(n=3)$. ${ }^{*} P=0.029$, ${ }^{\star \star} P=0.042$, ANOVA. (B) Phase-contrast microscopy analysis and number of MS per well in day 7 secondary T-MS and N-MS generated from primary MS in the presence or absence of IL-6 (10 $\mathrm{ng} / \mathrm{ml})$ and anti-IL-6 (1.5 $\mu \mathrm{g} / \mathrm{ml})$, respectively $(n=3)$. $\S P=0.027, \S \S P=0.020$, $\# P=0.048 ; \# P=0.035$, ANOVA plus post-hoc tests adjusted for multiple comparisons. (C) RT-PCR analysis of IL-6 mRNA in MCF-7 and day 2 MCF-7-derived spheroids and MCF-7(S) generated in the presence or absence of anti-IL-6 $(1.5 \mu \mathrm{g} / \mathrm{ml})$. Also shown are phase-contrast microscopy analysis and MCF-7(S) size distribution. $n$ denotes the number of spheroids counted for each sample. ${ }^{\circ} P=0.02$, Monte Carlo $\chi^{2}$ test. $\beta_{2} \mu$ was assessed as quantitative control for RTPCR analysis. Scale bars: $100 \mu \mathrm{m}$. gest that autocrine IL- 6 production could promote the aggressiveness of breast cancer cells.

IL-6 induces an autocrine IL-6 loop that triggers Notch-3-dependent aggressive behavior in MCF-7 cells. Prompted by these observations, we reasoned that IL- 6 might regulate the production of its own mRNA. Accordingly, we found that administration of IL-6 (10 ng/ $\mathrm{ml}$ ) upregulated IL-6 mRNA in MCF-7 cells and N-MS (Figure 9A). Furthermore, once exposed to IL-6 (10 ng/ml for 24 hours), MCF-7 cells expressed IL- 6 mRNA, even 2 weeks after the withdrawal of IL-6 from the medium (Figure 9B), suggesting that IL-6 autoregulation might perpetuate phenotypic changes caused by exposing breast cancer cells to IL-6. Compared with untreated MCF-7 cells, the cells described above displayed upregulation of Notch-3 and
CA-IX mRNA levels, paralleled by an enhancement in their invasive potential and an increase in MMP-2 activity (Figure 9B). The gene upregulation and the increase in invasive behavior of MCF-7 cells 2 weeks after withdrawal of IL- 6 was abolished by administration of anti-IL-6 $(1.5 \mu \mathrm{g} / \mathrm{ml})$, indicating that such features were dependent upon an autocrine IL-6 loop (Figure 9C). Notch-3 signaling was also required for this effect, because shNotch-3 MCF-7 cells did not show upregulation in CA-IX mRNA nor an enhancement of invasive potential, which were both observed in control MCF-7 cells 2 weeks after exposure to IL-6 (Figure 9D). As expected, the enhanced invasive capacity of IL-6-treated control MCF-7 cells was reduced by the transfection of CA-IX siRNA, but not scrambled siRNA (Figure 9E). These data support the argu- 


\section{A}
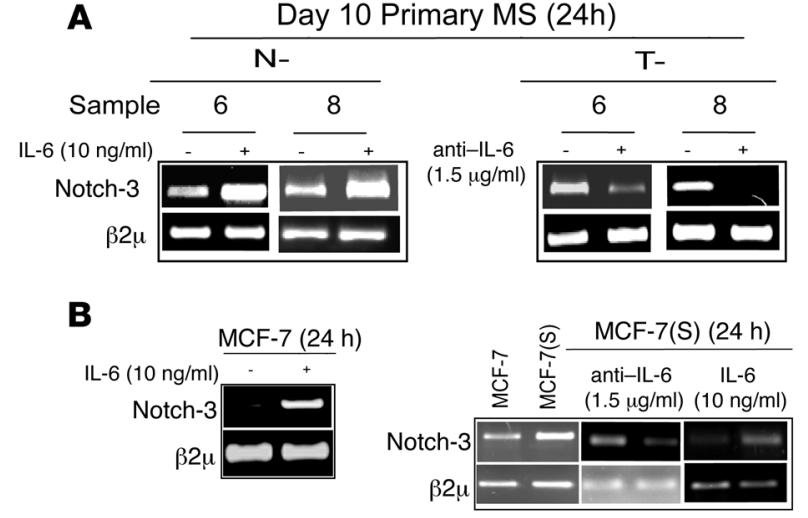

C

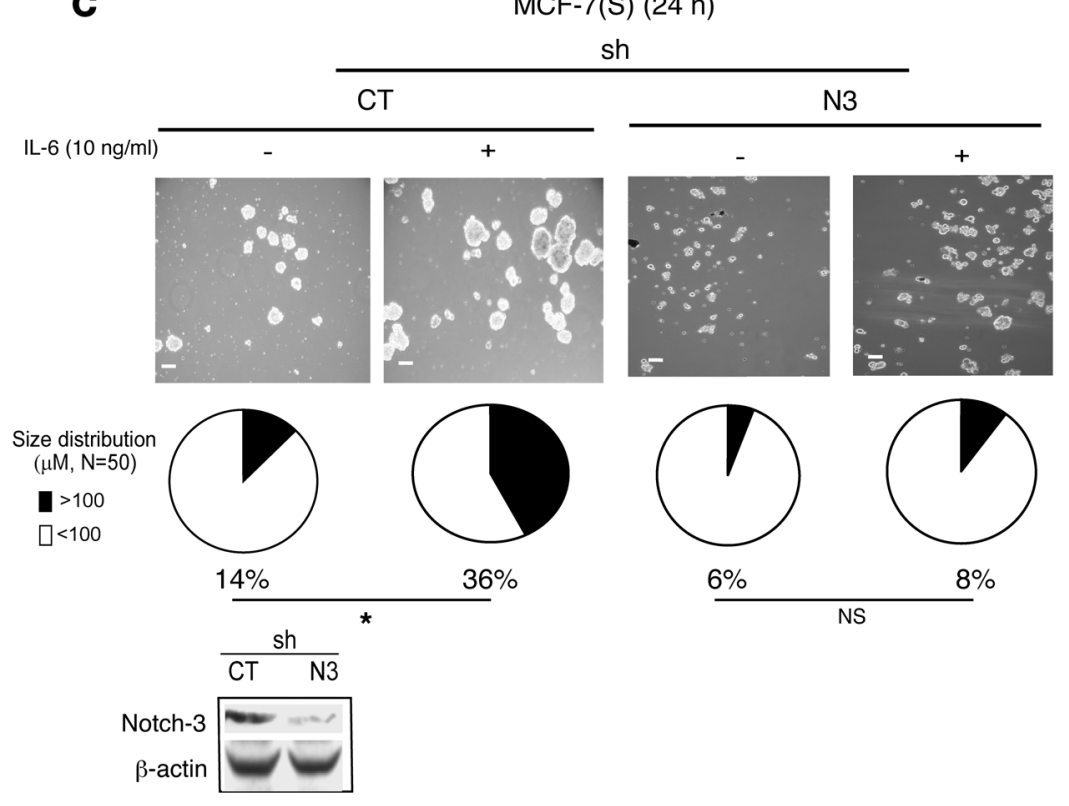

\section{Figure 3}

IL-6 induces Notch-3 gene upregulation and Notch-3dependent MCF-7(S) formation. (A) RT-PCR analysis of Notch-3 mRNA in day 10 primary N-MS in the presence or absence of IL-6 $(10 \mathrm{ng} / \mathrm{ml})$ and in T-MS in the presence or absence of anti-IL-6 $(1.5 \mu \mathrm{g} /$ $\mathrm{ml}$ ) for 24 hours. (B) RT-PCR analysis of Notch-3 mRNA in MCF-7 cells cultured in the presence or absence of IL-6 $(10 \mathrm{ng} / \mathrm{ml})$ and in MCF-7(S) in the presence or absence of anti-IL-6 $(1.5 \mu \mathrm{g} / \mathrm{ml})$ or IL-6 $(10 \mathrm{ng} / \mathrm{ml})$ for 24 hours. (C) Day 7 MCF-7(S) generated from MCF-7 cells infected with a pSuperPuro retroviral vector encoding a Notch-3-specific (N3) or control (CT) shRNA (sh) in the presence or absence of IL-6 (10 ng/ml). Phase-contrast microscopy analysis, MCF-7(S) size distribution ( $n$ denotes number of spheroids counted per sample), and Western blot analysis of Notch-3 and $\beta$-actin protein levels. ${ }^{\star} P=0.034$, Monte Carlo $\chi^{2}$ test. $\beta_{2} \mu$ was assessed as quantitative control for RT-PCR analysis. Scale bars: $100 \mu \mathrm{m}$.

partment in which stem/progenitor cells of the mammary gland are harbored in vivo (20). In this regard, recent data suggest that $\mathrm{CK}-5 / \mathrm{CD} 44^{+}$, Bmi-1-expressing cells represent cancer stem cells of head and neck squamous carcinoma (40). Overall, the available data support the notion that MS were substantially enriched in stem/ progenitor cells compared with the tissues from which they were obtained.

We provide evidence that T-MS obtained from node-invasive tumors expressed higher IL-6 mRNA levels than MS obtained from normal tissue of the same patients. Conversely, no difference was found when MS from scarcely invasive tumors were examined. We also found that IL-6 mRNA levels were readily detected ex vivo only in $\mathrm{CK}-5^{+}$basal-like breast carcinoma tissues, an

ment that an IL-6 autocrine loop could induce long-term enhancement in the aggressive features of breast cancer cells by sustaining upregulation of the Notch-3/CA-IX axis.

\section{Discussion}

The present work was prompted by the remarkably consistent finding that high IL-6 serum levels in breast cancer patients are associated with poor outcome and by the accumulating evidence suggesting that IL- 6 exerts a direct role in the upregulation of malignant features in breast cancer cells (1-8). Herein we investigated the physiological effects and regulation of IL- 6 in MS, which can be considered a suitable in vitro model for normal and tumor stem/progenitor cells of the mammary gland (21-27).

In regard to the stem cell phenotype of MS, we show here that MS express a variety of genes that are upregulated in normal and cancer stem cell from various tissues, such as Bmi-1 (23, 40), CD44 $(28,29)$, Oct-4 (27), BCRP-I (33), and CD133 $(31,32)$. In particular, $\mathrm{N}-\mathrm{MS}$ and T-MS are almost entirely composed of CD $44^{+} \mathrm{CD} 24^{-}$ cells (the so-called breast cancer stem cell phenotype; refs. 27, 28, 41 ) and a subpopulation of cells (differing 10\%-20\% in N-MS and T-MS) expressing CD133 protein. Moreover, N-MS and T-MS express the CK-5 gene, which characterizes the basal cell com- uncommon form of biological aggressive breast carcinoma with stem cell-like features, including high levels of CD133 and CD44 expression (34-37). We also showed that these tumors expressed high levels of the stem cell regulatory gene Bmi-1, which was recently shown to be expressed at high levels in T-MS compared with their differentiated epithelial progeny (23). In addition, Bmi-1 is also upregulated in CD $44^{+} \mathrm{CD} 24^{-}$breast cancer cells (23) and is highly expressed in a $\mathrm{CK}-5 / \mathrm{CD} 44^{+}$subpopulation of putative head and neck squamous carcinoma cancer stem cells (40). We also document that like basal-like carcinoma cells, T-MS also expressed CK-5/14, EGFR, CD133, Bmi-1, and IL-6. Thus T-MS derived from ductal breast carcinoma would appear to possess at least some of the stem cell-like characteristics of basal-like breast carcinoma. Our findings on basal-like breast carcinomas support the hypothesis that IL-6 gene expression is related to breast cancer stem cell phenotype. Accordingly, it has been shown that IL- 6 gene expression is high in breast cancer cell lines enriched in CD44 ${ }^{+} \mathrm{CD} 24^{-}$ invasive cells (16). Moreover, IL-6 gene expression showed up in MCF-7-derived spheroids (our present results), which have been shown to contain a high proportion of CD $44^{+} \mathrm{CD} 24^{-}$cells (38). Overall, these data support the existence of a tight relationship between cancer stem cells and IL-6 expression. 
A

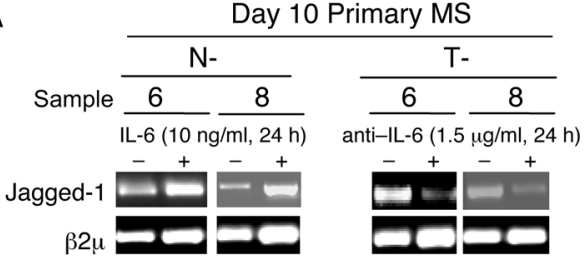

B

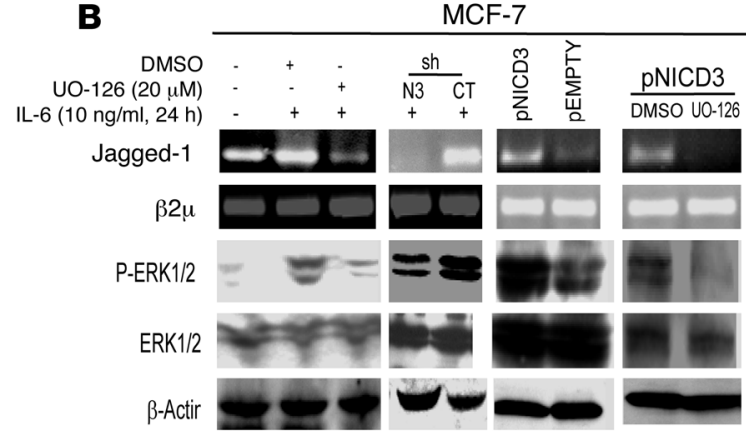

C

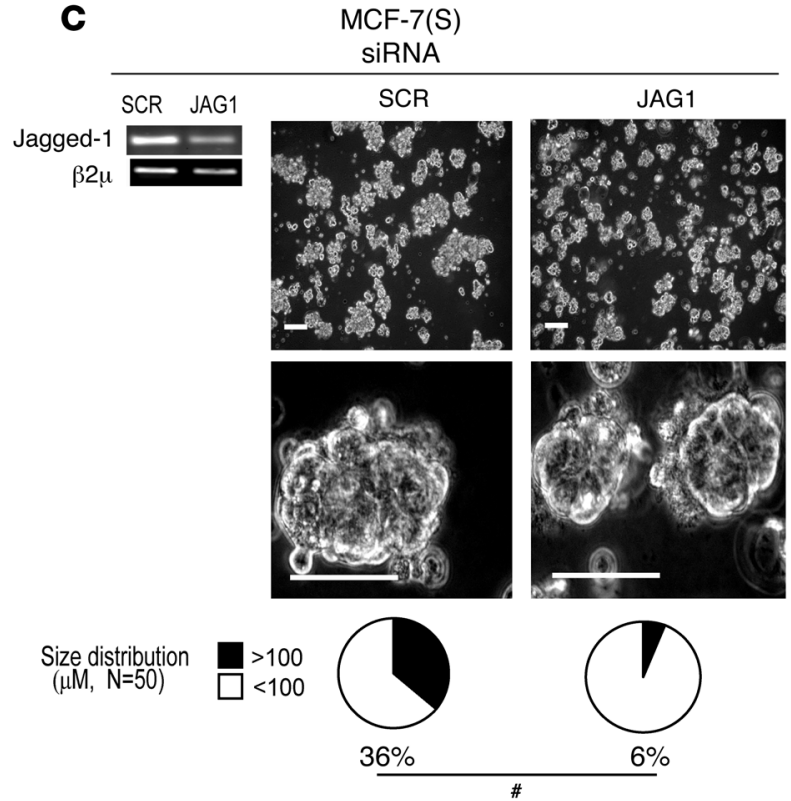

\section{D}

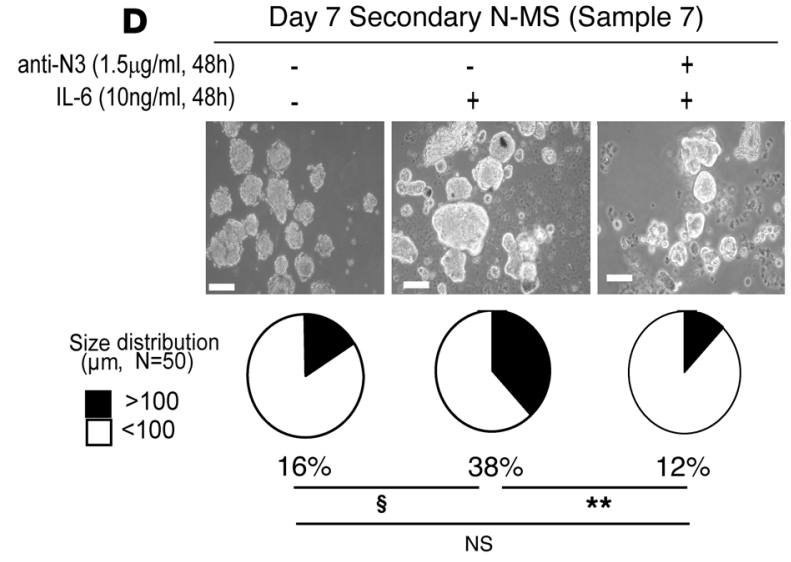

E
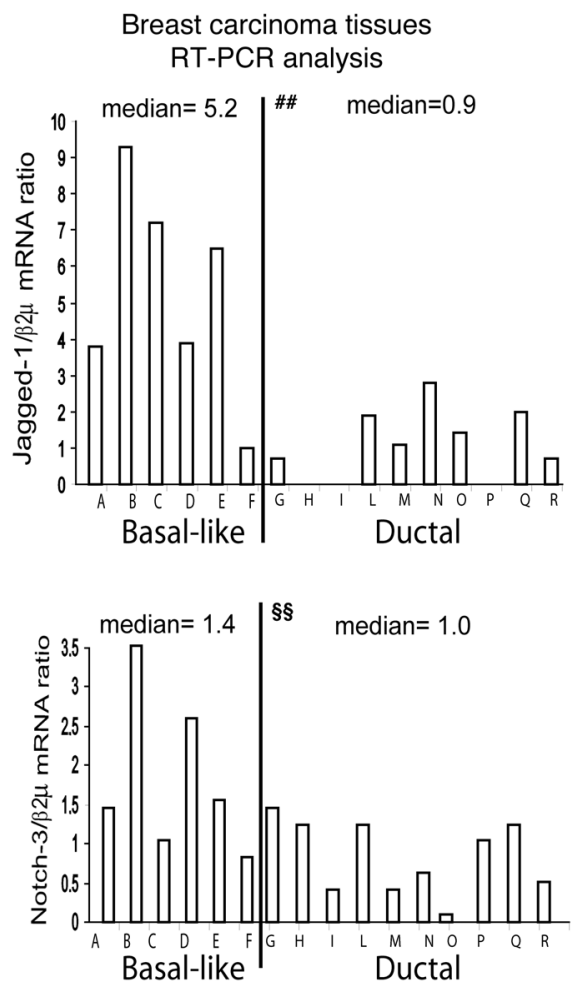

Figure 4

Notch-3/Jagged-1 interplay sustains MCF-7(S) formation and MS self-renewal. (A) Day 10 primary N-MS and T-MS cultured in the presence or absence of IL-6 $(10 \mathrm{ng} / \mathrm{ml})$ or anti-IL-6 $(1.5 \mu \mathrm{g} / \mathrm{ml})$ for 24 hours. RT-PCR analysis of Jagged-1 mRNA. (B) RT-PCR analysis of Jagged-1 mRNA and Western blot analysis of phosphorylated ERK and total ERK protein in MCF-7 cells exposed to IL-6 (10 ng/ml) in the presence or absence of the MEK1 inhibitor UO-126 (20 $\mathrm{MM}$ ) or DMSO for 24 hours, in shNotch-3 and control MCF-7 cells exposed to IL-6 (10 ng/ml for $24 \mathrm{hours),} \mathrm{in} \mathrm{MCF-7}$ cells transfected with $1 \mu \mathrm{g}$ pNICD3 or empty control vector (pEMPTY) for 24 hours, and in MCF-7 cells transfected with pNICD3 in the presence or absence of UO-126 (20 $\mu \mathrm{M})$ or DMSO. (C) Day 7 MCF-7(S) generated from MCF-7 cells transfected with Jagged-1-specific or scrambled (JAG1 and SCR, respectively) siRNA (1 $\mu \mathrm{g}, 72$ hours' pre-exposure). RT-PCR analysis of Jagged-1 mRNA, phase-contrast microscopy analysis, and MCF-7(S) size distribution. ${ }^{\#} P=0.001$, Monte Carlo $\chi^{2}$ test. (D) Day 7 secondary N-MS generated in the presence of IL-6 (10 ng/ml) and in the presence or absence of anti-N3 mAb, which blocks Notch-3 activity $(1.5 \mu \mathrm{g} / \mathrm{ml})$. Shown are phase-contrast microscopy and N-MS size distribution $(n$ denotes number of spheroids counted per sample). ${ } P=0.039,{ }^{\star \star} P=0.009$, Monte Carlo $\chi^{2}$ plus post-hoc tests adjusted for multiple comparisons. (E) RT-PCR analysis of Jagged- 1 and Notch-3 mRNA (ratio to $\beta_{2} \mu$ ) in basal-like or ductal carcinoma tissues. $\# \#=0.005, \$ \S P=0.042$, Mann-Whitney test. $\beta_{2} \mu$ was assessed as quantitative control for RT-PCR; $\beta$-actin was assessed as quantitative control for Western blot. Scale bars: $100 \mu \mathrm{m}$.

Moreover, we also provide evidence that the effects of IL-6 on MS required a functional Notch-3 signaling pathway. Notch-3, a member of the stem cell regulatory Notch family that governs stem cell homeostasis and turnover across species, modulates morphogenetic processes in the mammary gland; when hyperexpressed in transgenic mice, Notch-3 also promotes mammary gland carcinogenesis (17). Interestingly, the Notch-3-dependent activation of the ERK pathway has been reported in both lung cancer and lymphoma cell models $(26,42,43)$. Here, we show that Notch-3dependent ERK activation in breast cancer via IL- 6 targeted the 
A

Day 10 Primary N-MS (sample 11)

IL-6 (10 ng/ml, $24 \mathrm{~h})-\quad+$
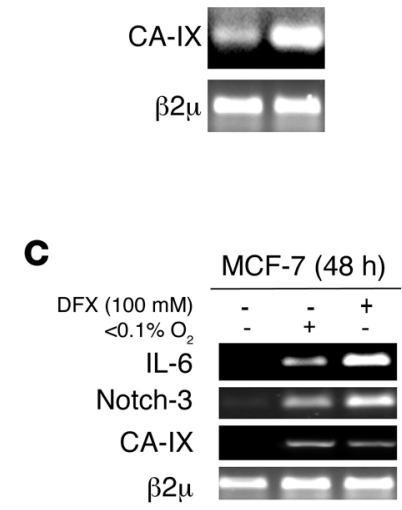

$\beta 2 \mu$
B

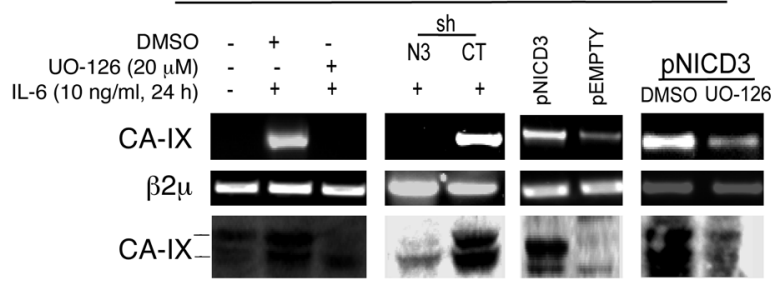

Day 10 Primary MS (sample 11)

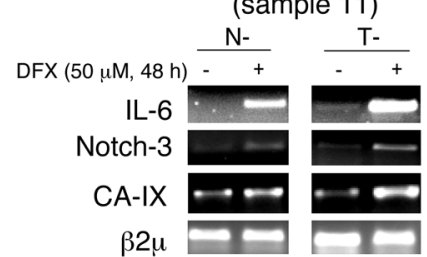

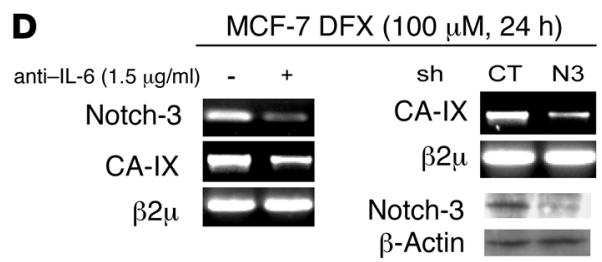

\section{Figure 5}

IL-6/Notch-3 cross-talk promotes the upregulation of CA-IX mRNA and protein. (A) RT-PCR analysis of CA-IX mRNA in day 10 primary N-MS cultured in the presence or absence of IL-6 (10 $\mathrm{ng} / \mathrm{ml}$ ) for 24 hours. (B) RT-PCR analysis of CA-IX mRNA and Western blot analysis of CA-IX (phosphorylated ERK, total ERK, and $\beta$-actin protein levels shown in Figure 4B) in MCF-7 cells exposed to IL-6 (10 ng/ml for 24 hours) in the presence or absence of UO-126 (20 $\mu \mathrm{M})$ or DMSO, in shNotch-3 and control MCF-7 cells exposed to IL-6 (10 ng/ml for 24 hours), in MCF-7 cells transiently transfected with pNICD3/pEMPTY vector $(1 \mu \mathrm{g})$, and in MCF-7 cells transfected with pNICD3 and coadministered with UO-126 $(20 \mu \mathrm{M})$ or DMSO for 24 hours. (C) RT-PCR analysis of IL-6, Notch-3, and CA-IX mRNA in MCF-7 cells exposed to low oxygen $\left(<0.1 \% \mathrm{O}_{2}\right)$ or $100 \mu \mathrm{M} \mathrm{DFX}$ and in N-MS and T-MS exposed to $50 \mu \mathrm{M}$ DFX for 48 hours. (D) RT-PCR analysis of Notch-3 and CA-IX mRNA in MCF-7 cells in the presence or absence of anti-IL-6 $(1.5 \mu \mathrm{g} / \mathrm{ml})$ and in shNotch-3 and control-infected MCF-7 cells exposed to DFX (100 $\mu \mathrm{M}$ for 24 hours), Western blot analysis of Notch-3 and $\beta$-actin protein. $\beta_{2} \mu$ was assessed as quantitative control for RT-PCR analysis.

creating a favorable environment for the activation of the extracellular matrix degrading enzymes such as MMP-2 (45, 46). Remarkably, higher MMP-2 expression has been associated with poor prognosis in breast cancer (46). In addition, CA-IX hyperexpression has been associated with reduced survival and poor outcome in breast cancer patients $(47,48)$, and it has also been found to be overexpressed in basallike breast carcinomas $(49,50)$. Overall, the upregulation of CA-IX and Jagged-1 adds to a growing number of genes (i.e., CK-5, CK-14, EGFR, CD133, CD44, $B m i-1$, and $I L-6)$ that also convey a tight similarity between T-MS and basal-like breast carcinoma. Finally, we present data regarding the autocrine IL-6 loop in breast cancer cells. In particular, we showed that IL- 6 upregulated its own mRNA, thus perpetuating the effects of transient IL-6 exposure of breast cancer cells. In addition, this autocrine IL- 6 loop required active Notch-3 expression. Hence, our data suggest that the upregulation of IL- 6 gene expression in response to stress conditions (hypoxia) or to inflammation (IL-6 itself) may be maintained by an autocrine mechanism in Notch-3 stem/progenitor cells of the mammary gland.

Of note, in this investigation we show that IL- 6 triggers self renewal and the invasive capacity of MS obtained from normal mammary tissue. At first glance, this finding could be surprising. However, we must consider that the inflammatory response is a physiologic mechanism aimed at repairing damaged activation of Jagged-1, which belongs to a family of Notch ligands $(18,19)$, and $C A-I X$, a hypoxia survival gene. Importantly, siRNA knockdown experiments revealed that both Notch-3 and Jagged-1 were functionally required for spheroid formation and for MS self renewal. Consequently, our data suggest that IL- 6 may trigger a potential autocrine/paracrine Notch-3/Jagged-1 loop to boost stem/progenitor self renewal in the mammary gland. Furthermore, in agreement with previous findings $(18,19,37)$, we show that Jagged-1 gene expression correlated with a basal-like breast carcinoma phenotype. Because the IL- 6 receptor is expressed at higher levels in basal-like breast carcinomas than in other breast cancer subtypes (34), we hypothesize that the IL-6/Notch-3/Jagged- 1 axis may confer a growth advantage to basal-like carcinoma cells and also to ductal breast carcinoma stem cells.

We also showed that the CA-IX hypoxia survival gene was upregulated by IL- 6 and sustained the invasive potential of breast cancer cells and MS. CA-IX catalyzes carbonic dioxide hydrolysis (44) to facilitate survival under conditions of hypoxia by increasing the concentration of basic equivalents in the cytoplasm, which simultaneously lowers the $\mathrm{pH}$ in the extracellular space, thereby tissues (51). It is therefore conceivable that stem/progenitor cells are able to respond to an inflammatory stimulus (such as IL-6) by a process that promotes proliferation (and self renewal) and stimulates the migration toward locations where tissue repair is required. In this regard, we examined the capacity of MS to generate 3 -dimensional structures, that is, to migrate into matrigel and to generate multi-acinar and acinar/ductal structures (ref. 52 and Supplemental Methods). As shown in Supplemental Figure 5, we obtained preliminary evidence that such a morphogenic capacity of MS (upper panel), as well as that of cells derived from the trypsin disgregation of normal MS (lower panel), may be enhanced by IL-6 administration. Indeed, only in IL-6-administered cultures did we observe features recalling acinar structure with a hollow lumen and ductal branching (arrow and arrowhead, respectively, lower panel). These data, together with those reported previously (24), support the hypothesis that Notch signaling plays a role in mammary gland morphogenesis and therefore suggest that IL-6 may enhance the morphogenic capacity of mammary gland stem/ progenitor cells. Instead, we observed that CD44/CK-5-expressing T-MS (Supplemental Figure 6, left panel) plated on plastic and on 
A MCF-7 cell death assay
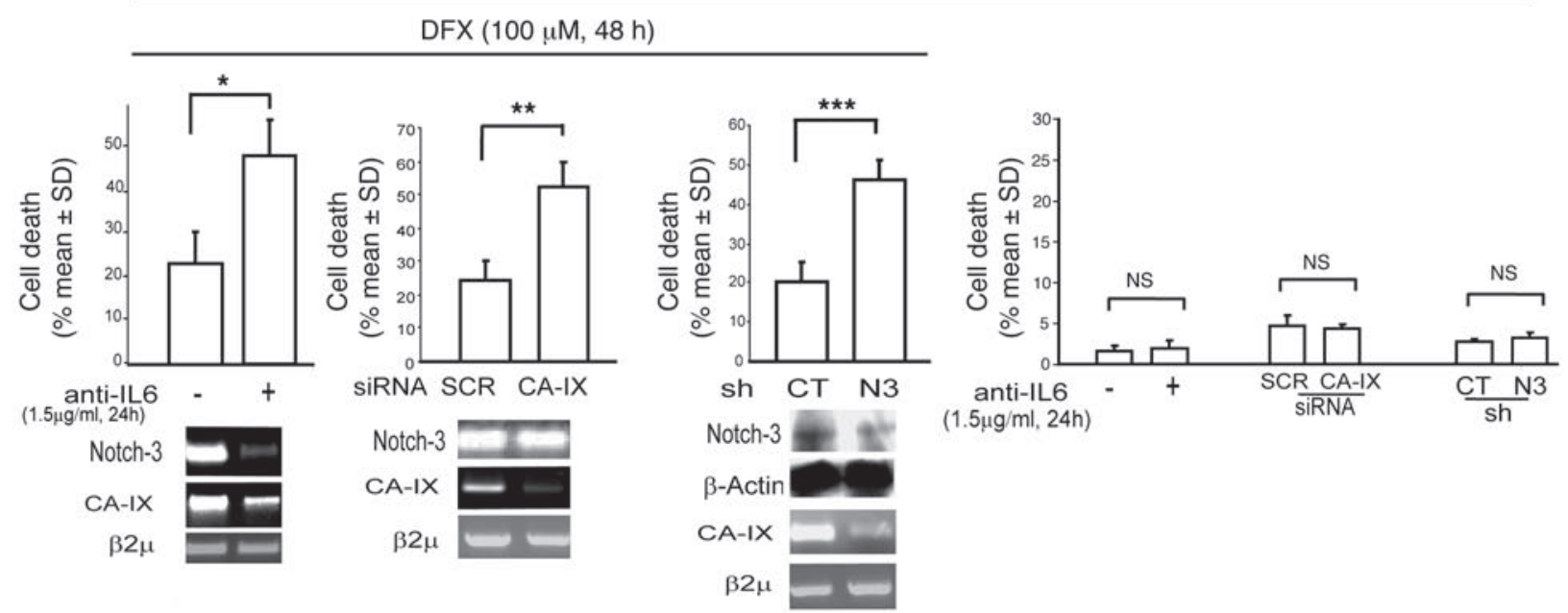

B

Day 7 secondary T-MS DFX $(50 \mu \mathrm{M}, 48 \mathrm{~h})$ cell death assay
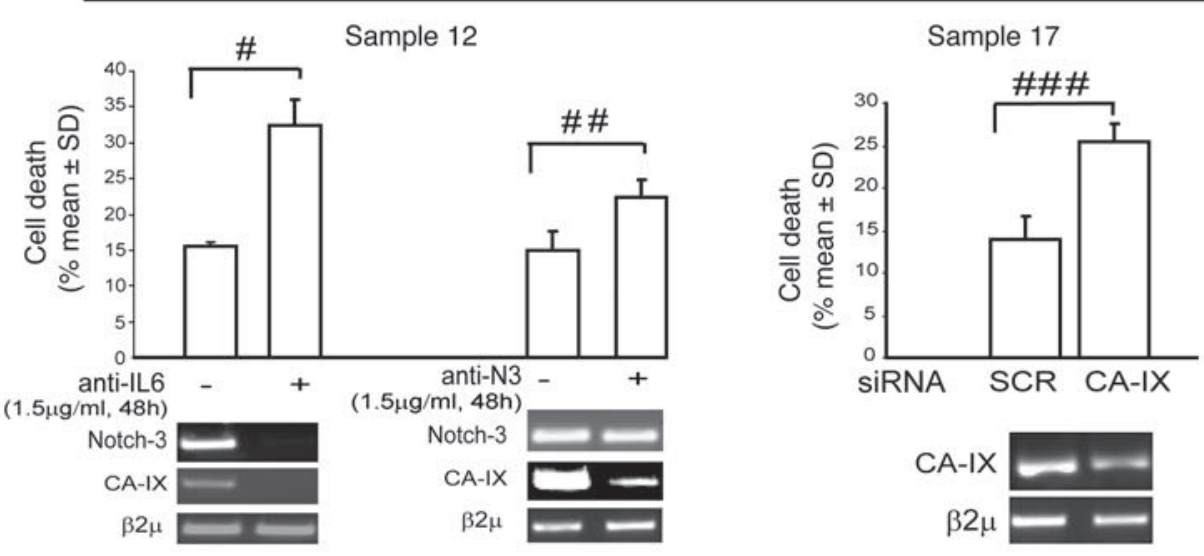

C

Breast carcinoma tissues
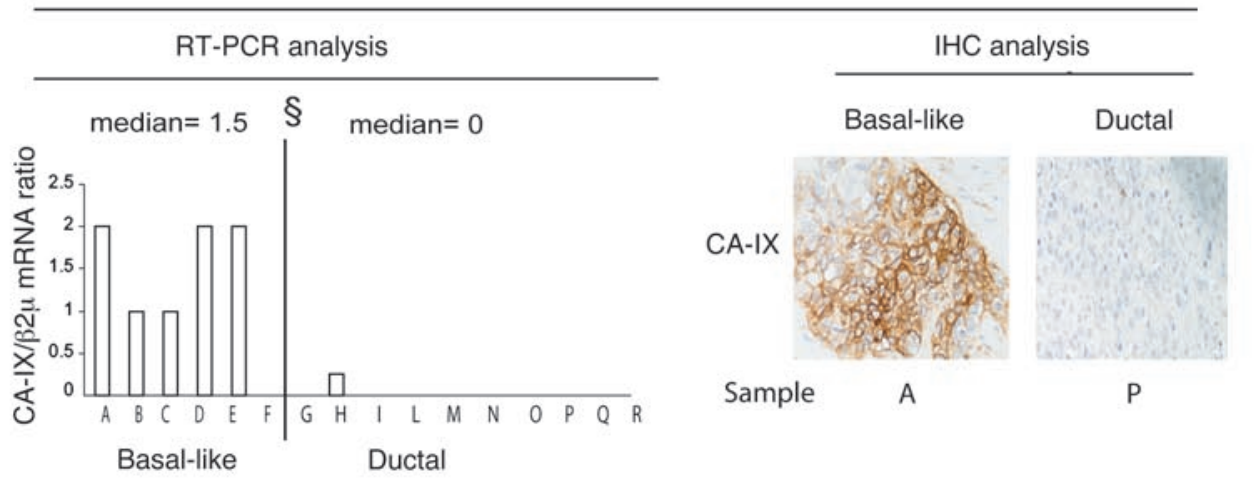

\section{Figure 6}

The IL-6/Notch-3/CA-IX axis promotes hypoxia survival. (A) MCF-7 cells in the presence or absence of DFX (100 $\mu \mathrm{M}$ for 48 hours) and in the presence or absence of anti-IL-6 $(1.5 \mu \mathrm{g} / \mathrm{ml}$ for 24 hours), with transient transfection with the CA-IX-specific or scrambled siRNA ( $1 \mu \mathrm{g}$ for 72 hours), and shNotch-3 and control MCF-7 cells. Shown are Western blot analysis of Notch-3 and $\beta$-actin protein and cell death analysis and RT-PCR analysis of Notch-3 and CA-IX mRNA $(n=3) .{ }^{*} P=0.017,{ }^{* \star} P=0.008,{ }^{* *} P=0.002$, ANOVA. (B) Cell death analysis and RT-PCR analysis of Notch-3 and CA-IX mRNA in day 7 secondary T-MS exposed to $50 \mu \mathrm{M}$ DFX for 48 hours in the presence or absence of anti-IL-6 $(1.5 \mu \mathrm{g} / \mathrm{ml}$ for 48 hours) or anti-N3 $(1.5 \mu \mathrm{g} / \mathrm{ml}$ for 48 hours $)$ or transfected with CA-IX or scrambled siRNA (1 $\mu \mathrm{g}$ for 72 hours). $n=3$ per group. ${ }^{\#} P=0.022$, ${ }^{\#} P=0.025,{ }^{\# \#} P=0.044$, ANOVA. (C) RT-PCR analysis and representative IHC analysis of CA-IX protein expression of breast carcinoma tissues from patients affected by basal-like or ductal breast carcinoma (see Table 2 ). Data are shown as CA-IX/ $\beta_{2} \mu \mathrm{mRNA}$ ratio. $\S P=0.002$, Mann-Whitney test. $\beta_{2} \mu$ was assessed as quantitative control for RT-PCR analysis. Scale bar: $100 \mu \mathrm{m}$. 
A MCF-7 Invasion assay (24 h)
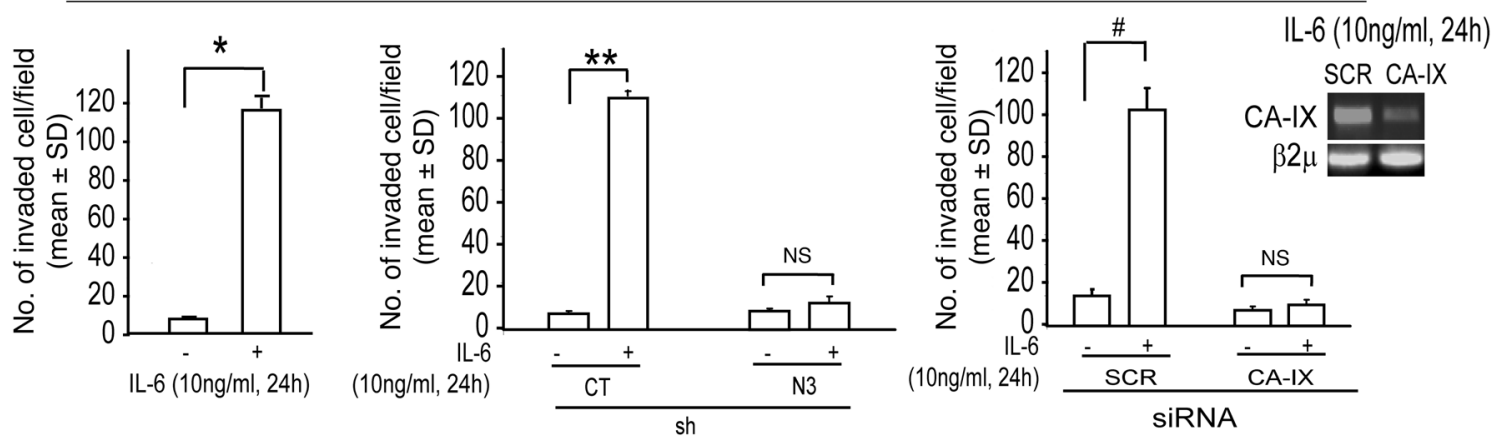

B Day 7 secondary T-MS Invasion assay (24 h)
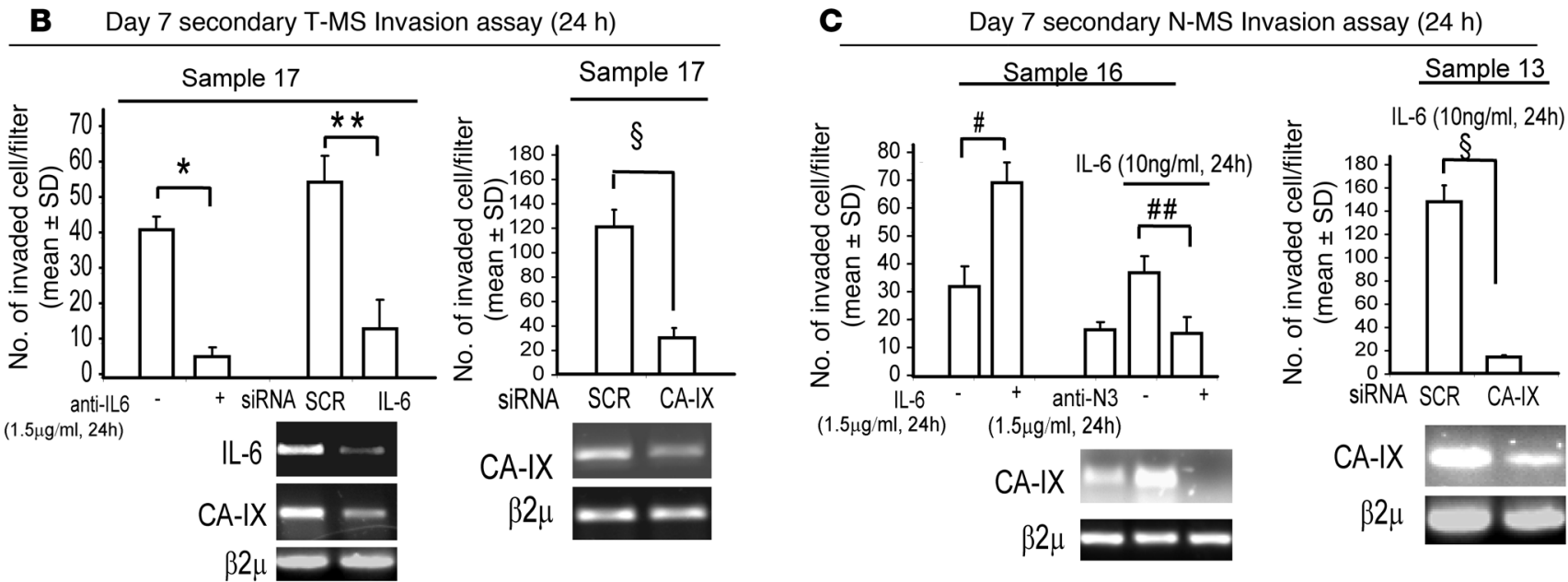

D

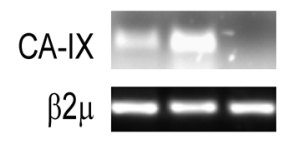

CA-IX

$\beta 2 \mu$

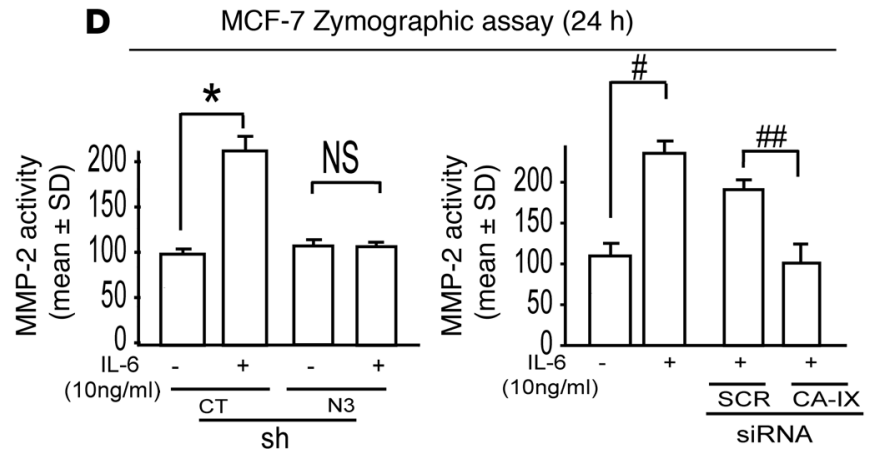

Figure 7

IL-6/Notch-3 cross-talk enhances the invasive potential of MS and MCF-7 cells by means of CA-IX mRNA upregulation. (A) Boyden invasion chamber assay in MCF-7 cells, in shNotch-3 and control MCF-7 cells, and in MCF-7 cells transiently transfected with scrambled or CA-IX siRNA (1 $\mu \mathrm{g}, 72$ hours' pre-exposure), in the presence or absence of IL-6 (10 ng $/ \mathrm{ml}$ for 24 hours). $n=5$ per group. ${ }^{*} P=0.0001,{ }^{* *} P=0.0001$, $\# P=0.0001$, ANOVA. Inset: RT-PCR analysis of CA-IX mRNA in cells administered scrambled or CA-IX siRNA. (B) Boyden chamber invasion assay of day 7 secondary T-MS in the presence or absence of anti-IL6 $(1.5 \mu \mathrm{g} / \mathrm{ml}$ for $24 \mathrm{~h})$ or transfected with IL-6 or CA-IX or scrambled siRNA $\left(1 \mu \mathrm{g}, 72\right.$ hours' pre-exposure). $n=3$ per group. ${ }^{*} P=0.003,{ }^{* *} P=0.042, \$ P=0.0001$, ANOVA. RT-PCR analysis of IL-6 and CA-IX mRNA is shown. (C) Boyden chamber invasion assay of day 7 secondary N-MS exposed to IL-6 $(10 \mathrm{ng} / \mathrm{ml}$ for 24 hours) in the presence or absence of anti-N3 $(1.5 \mu \mathrm{g} / \mathrm{ml}$ for 24 hours) or scrambled or CA-IX siRNA (1 $\mu \mathrm{g}, 72$ hours' pre-exposure). $n=3$ per group. $\# P=0.036$, \#\# $P=0.037$, $\S P=0.0001$, ANOVA. RT-PCR analysis of IL-6, CA-IX, and $\beta_{2} \mu$ mRNA is shown. (D) Zymographic analysis of MMP-2 activity in shNotch-3 and control MCF-7 cells in the presence or absence of IL-6 (10 ng/ml for 24 hours) and in MCF-7 cells exposed to IL-6 (10 ng/ml for 24 hours) transfected with CA-IX or scrambled siRNA ( $1 \mu \mathrm{g}, 72$ hours' pre-exposure). $n=3$ per group. ${ }^{*} P=0.032,{ }^{\#} P=0.025$, ${ }^{\#} P=0.027$, ANOVA.

matrigel produce cells that lose the expression of some stem cell markers (such as Oct-4 and CK-5) and acquire the expression of CD24, but cannot generate 3-dimensional structures in matrigel (upper right panel), whereas both luminal (CK-18) and myoepithe- lial (CK-14) markers are expressed (lower right panel). This finding supports the notion that N-MS and T-MS from the same individual have different functional properties and that the latter are endowed with an aberrant/defective capacity to differentiate (24). 
A

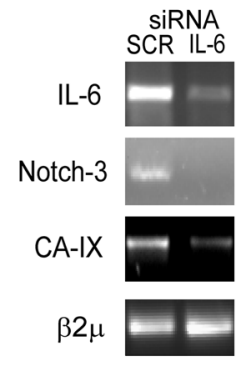

B

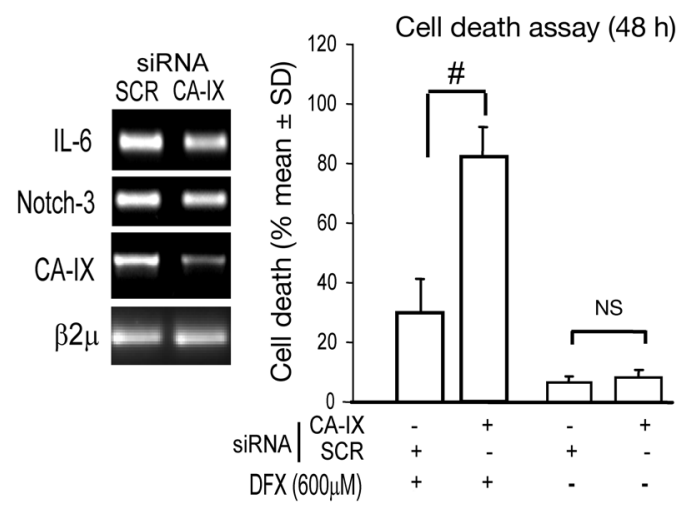

C

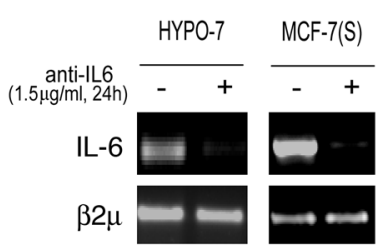

Cell death assay $(48 \mathrm{~h})$

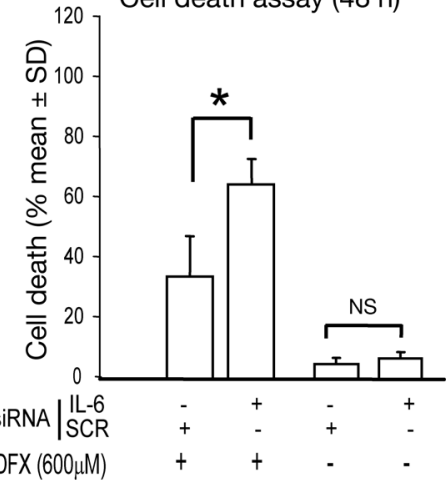

Day 10 Primary T-MS

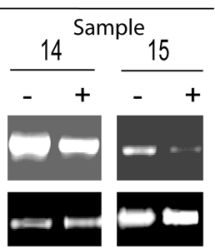

HYPO-7

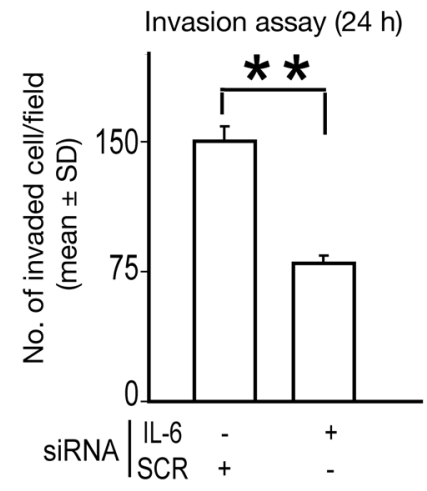

HYPO-7

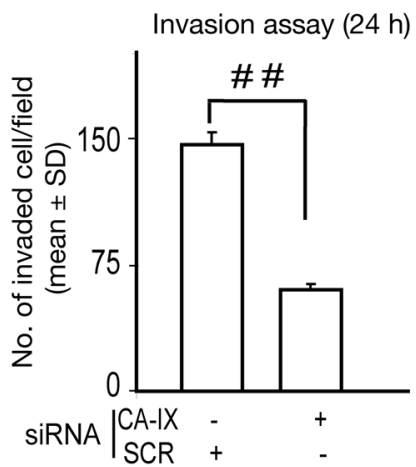

Zymographic assay (24 h)
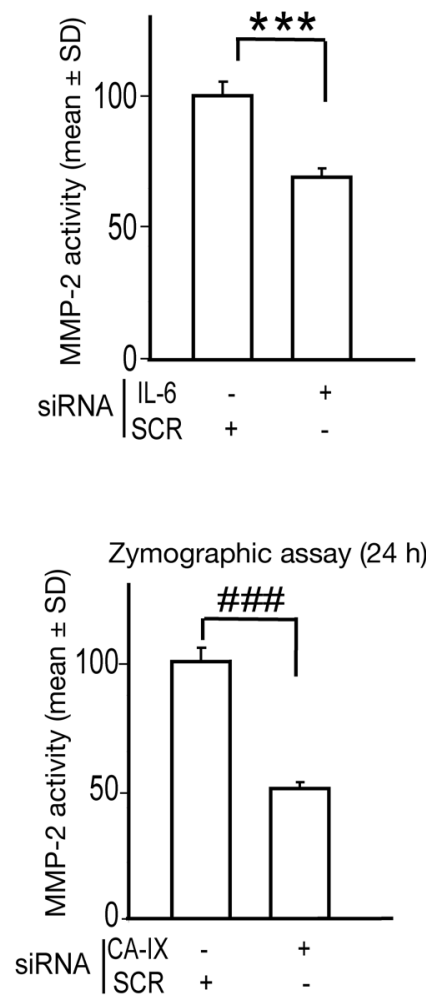

Figure 8

Autocrine IL-6 loop sustains a CA-IX-dependent malignant phenotype in HYPO-7 cells. (A) HYPO-7, a MCF-7-derived cell population, in the presence of IL-6 or scrambled siRNA ( $1 \mu \mathrm{g}, 48$ hours' pre-exposure). RT-PCR analysis of IL-6, Notch-3, and CA-IX mRNA; cell death analysis in the presence of DFX ( $600 \mu \mathrm{M}$ for 48 hours); and Boyden chamber invasion assay $(n=5)$ and zymographic analysis $(n=3)$ of MMP-2 activity (24 hours). ${ }^{*} P=0.042,{ }^{*} P=0.0001,{ }^{* \star} P=0.015$, ANOVA. (B) HYPO-7 cells in the presence of CA-IX or scrambled siRNA (1 $\mu \mathrm{g}, 48 \mathrm{hours}$ ' preexposure). RT-PCR analysis of IL-6, Notch-3, and CA-IX mRNA; cell death analysis in the presence of DFX (600 $\mu \mathrm{M}$ for 48 hours); and Boyden

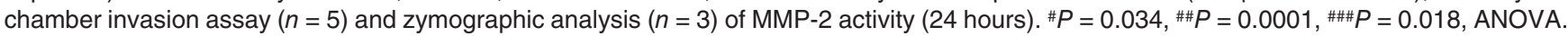
(C) HYPO-7 cells, MCF-7(S), and T-MS exposed to anti-IL-6 $(1.5 \mu \mathrm{g} / \mathrm{ml})$ for 24 hours. RT-PCR analysis of IL-6 mRNA level. $\beta_{2} \mu$ was assessed as quantitative control for RT-PCR analysis.

It may be indeed argued that the N-MS studied in this investigation were obtained from breast cancer patients. However, although a field effect can not be completely excluded, it has been recently demonstrated that in the human breast, no detectable changes in gene expression are found when non-neoplastic tissues from cancer patients are compared with normal samples from women without cancer (53). Nevertheless, although it is reasonable that IL- 6 could participate in the homeostatic mechanism of a normal mammary gland, it has long been established that chronic inflammation, and the sustained upregulation of its mediators, is a cancer-predisposing condition (51). In this regard, recent data indicate that inflammatory cells such as macrophages and lymphocytes promote cancer growth in the mammary gland $(54,55)$. Although the role of inflammation in breast cancer has long been criticized, recent experimental and epidemiological data indicate that breast cancer growth may be promoted by local and distant inflammatory processes (such as those in the gut), in agreement with the hypothesis that soluble factors link inflammation to breast cancer (56). In regard to this issue, it is worth mentioning that IL-6 serum levels increase with age (30) and that aging is a major risk factor for breast cancer (57). Hence, we speculate that altered IL-6 gene expression in dysregulated mammary gland/stem progenitor cells 
A

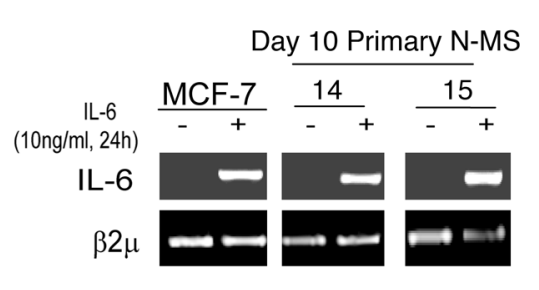

C

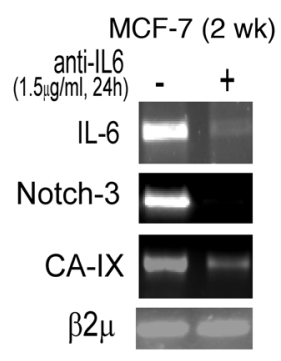

$\mathbf{E}$

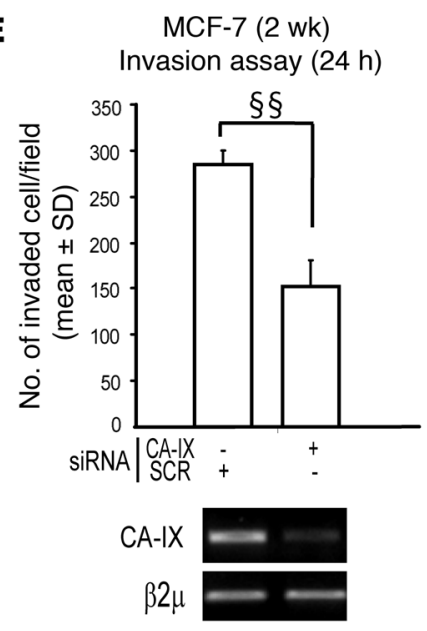

B MCF-7

\begin{tabular}{|c|c|c|}
\hline $\begin{array}{r}\text { IL-6 } \\
(10 \mathrm{ng} / \mathrm{ml}, 24 \mathrm{~h})\end{array}$ & + & $(1 w k)(2 v$ \\
\hline IL-6 & $\theta$ & $\because 6$ \\
\hline Notch-3 & $\sim$ & -4 \\
\hline CA-IX & G & $=$ \\
\hline$B 2$ & & \\
\hline
\end{tabular}

D
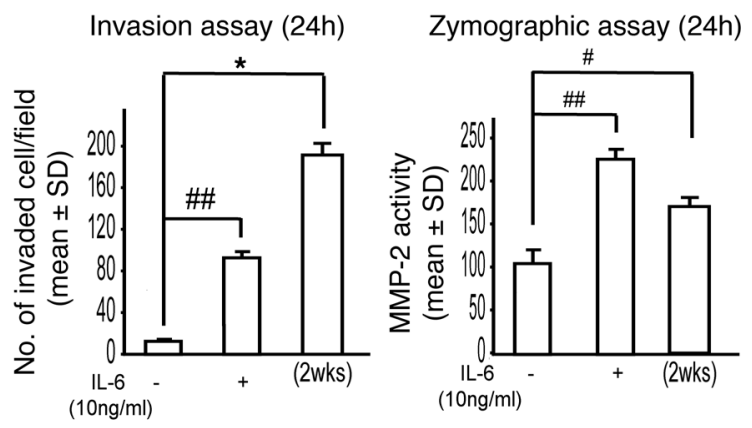

Invasion assay (24h)

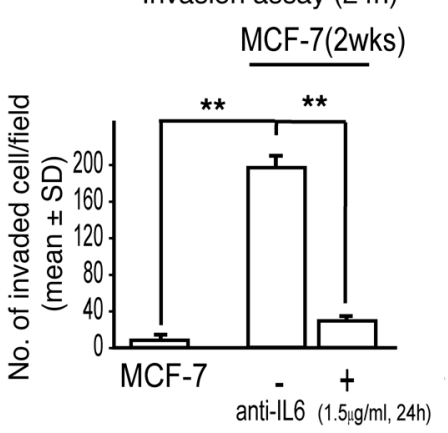

\section{MCF-7 (2 wk)}
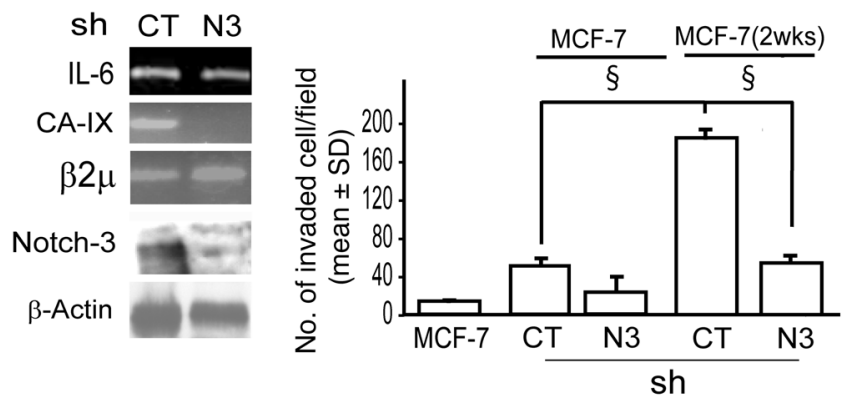

\section{Figure 9}

Autocrine IL-6 loop sustains a Notch-3/CA-IX-dependent aggressive phenotype in MCF-7 cells. (A) RT-PCR analysis of IL-6 mRNA in MCF-7 cells and N-MS exposed to IL-6 (10 ng/ml) for 24 hours. (B) MCF-7 cells exposed to IL-6 (10 ng/ml for 24 hours) and assessed at various times (1 or 2 weeks) after the withdrawal of the cytokine. RT-PCR analysis of IL-6, Notch-3, and CA-IX mRNA and Boyden chamber invasion assay $(n=5)$ and zymographic analysis $(n=3)$ of MMP-2 activity (24 hours). ${ }^{*} P=0.010,{ }^{\#} P=0.012$, $\# P=0.002$, ANOVA with post-hoc test for multiple comparisons. (C) MCF-7 cells exposed to IL-6 $(10 \mathrm{ng} / \mathrm{ml})$ for 24 hours and assessed 2 weeks after cytokine withdrawal in the presence or absence of anti-IL-6 $(1.5 \mu \mathrm{g} / \mathrm{ml})$ for 24 hours. RT-PCR analysis of IL-6, Notch-3, and CA-IX mRNA and Boyden chamber invasion assay (24 hours). $n=5$ per group. ${ }^{\star \star} P=0.004$, ANOVA with post-hoc test for multiple comparisons. (D) RT-PCR analysis of IL- 6 and CA-IX mRNA, Western blot analysis of Notch-3 and $\beta$-actin protein level, and Boyden chamber invasion assay ( 24 hours) in shNotch-3 and control MCF-7 cells either untreated or exposed to IL- 6 for 24 hours and assessed 2 weeks after cytokine withdrawal $(n=5)$. $\$ P=0.001$, ANOVA with post-hoc test for multiple comparisons. (E) Boyden chamber invasion assay (24 hours) and RT-PCR analysis of CA-IX mRNA in cells as in C and D transfected with CA-IX or scrambled siRNA ( $1 \mu \mathrm{g}, 48$ hours' pre-exposure). $n=5$ per group. $\S \S P=0.002$, ANOVA. $\beta_{2} \mu$ was assessed as quantitative control for RT-PCR analysis.

may be a contributory factor linking aging to breast cancer risk. In conclusion, the findings indicate that IL- 6 is a potent promoter of malignant features in Notch-3 expressing normal and tumor stem/progenitor cells of the mammary gland.

\section{Methods}

Chemicals and reagents. Anti-Notch-3, a mAb that blocks the activation of Notch-3 protein by inhibiting the Notch-3/Jagged-1 interaction, was purchased from R\&D. Anti-IL-6, a mAb that blocks the IL- 6 receptor/ligand interaction, and recombinant human IL-6 were purchased from SigmaAldrich. DFX (Sigma-Aldrich) was used as hypoxia mimetic (26); UO-126 (Sigma-Aldrich) was used as MEK1 inhibitor.

Generation of MS from normal and ductal breast carcinoma tissue specimens. Seventeen fresh surgical specimens, obtained from patients with ductal breast carcinoma who underwent quadrantectomy or mastectomy, were collected to generate MS (Table 1). Normal and tumor samples were histologically characterized (as reported below) to ensure the proper classification of normal and tumor tissue. Particular care was paid to generate MS from specimens in which only normal or tumor tissues were detectable at histological examination. The set of samples consisted of a subset of tumor specimens $(n=3)$ in which the mRNA of the tumor tissues from which the MS originated was available as well as a subset of specimens $(n=14)$ in which even the normal tissue from the same patient was available (Table 1). MS were obtained as previously described (21-27), except that the methodology was downscaled to deal with low amounts of tissues (300-900 mg; ref. 26). Briefly, tissues were placed in sterile Epicult (StemCell Technologies), minced with sterile scalpels, and incubated for 6-12 hours in the presence of 1,000 U Collagenase/Hyaluronidase enzyme mix (StemCell Technologies). Samples were centrifuged at $80 \mathrm{~g}$ for 2 minutes, and the pellet was digested by Dispase and DNAse for 3 minutes (StemCell Technologies) and then pelleted 
at $450 \mathrm{~g}$ for 5 minutes. Pellets were re-suspended, filtered through a $40-\mu \mathrm{M}$ nylon mesh (BD), and plated into 1- or 3- $\mathrm{cm}^{2}$-well low attachment plates (Corning), filled with $3 \mathrm{ml}$ mammary epithelial growth medium (MEGM), and supplemented with B27 supplement (10 ng/ml EGF, $10 \mathrm{ng} / \mathrm{ml}$ bFGF, $10 \mu \mathrm{g} / \mathrm{ml}$ Insulin, $10^{-6} \mathrm{M}$ hydrocortisone, and ad-hoc aliquots Gentamycin and Amphotericine; Cambrex). Primary MS started forming after 4-6 days and were processed at day 10. Experimental procedures were performed on secondary MS, generated by incubating primary MS in $1 \times$ Trypsin-EDTA solution (Cambrex) for 3 minutes, followed by 2 washes in complete MEGM and filtration throughout a 40- $\mu \mathrm{m}$ nylon mesh. Self renewal of MS was tested by assessing the capacity of primary MS to generated secondary MS after trypsin disaggregation, as previously described (21-23, 26). Secondary MS were assessed at day 7. All the procedures were approved by Comitato Etico dell'Azienda Ospedaliera, University of Bologna, and written informed consent was obtained from patients.

IHC. IHC was performed on formalin-fixed, paraffin-embedded tumor samples (Tables 1 and 2) and on N-MS and T-MS, which were embedded in collagen (Sigma-Aldrich) 2 hours before fixation in formalin. Tissues were histologically classified according to WHO criteria (58) and graded following the classification described by Elston and Ellis (59). The tumors were also typed by nuclear grading and classified as mild, moderate, and severe nuclear atypia (graded 1, 2, and 3, respectively). Tumor size and axillary lymph node involvement were also recorded using pTNM (UICC) pathological staging criteria (59). Serial sections of formalin-fixed, paraffin-embedded samples were dewaxed, rehydrated, and subjected to antigen retrieval treatment. Tumor sections were stained using mAbs against estrogen receptor (ER; clone 1D5), CK-5 (clone D5/16B4), and EGFR (clone DAHK1-WT) obtained from DakoCytomation (Glostrup); ErbB-2 (HER-2; clone CB11) and CK-14 (clone LL002) from BioGenex Laboratories; and CA-IX (M-75; kindly provided by J. Pastorek, Slovak Academy of Sciences, Bratislava, Slovak Republic). Sections of N-MS and T-MS were stained with anti-CK-5, CK-14, EGFR, and CK-18 (clone KSB17; Sigma-Aldrich); Oct-4 (clone c-20; Santa Cruz); CD44 and CD24 (clone 156-3C11 and clone 24C02; Neomarkers); CD133 (Miltenyi Biotec); and E-cadherin (clone $\mathrm{NCH} 38$; DakoCytomation). Antigens were unmasked with Tris-EDTA, $\mathrm{pH}$ 9.0, at $98^{\circ} \mathrm{C}$ for 20 minutes, except for CA-IX antibody. Endogenous peroxidase activity was inhibited using a $0.5 \% \mathrm{H}_{2} \mathrm{O}_{2}$ solution in methanol for 20 minutes, and sections were processed for IHC with a non-biotin-amplified method (Novolink; Novocastra Laboratories). Stained immunoreaction was quantified by image cytometry using Cytometrica software $(\mathrm{C} \& \mathrm{~V})$. Sections were independently evaluated by 2 investigators, and controversial results were discussed and defined. For ER immunostaining, the percentage of the labeled nuclear area over the total neoplastic nuclear area was assessed (negative, $<10 \%$ nuclei; positive, $>10 \%$ nuclei). A semiquantitative assessment was applied for CK-5, CK-14, and EGFR evaluation: cases were considered positive when the immunopositive neoplastic population was greater than $10 \%$. HER-2 staining was scored according to the HercepTest FDA-approved grading system. The percentage of immunopositive cells in N-MS and T-MS was assessed on 3-5 sections (mean 100-300 cells).

Cell cultures. MCF-7 cells were grown in RPMI 1640 medium with $10 \%$ FBS (Euroclone). Hypoxia $\left(<0.1 \% \mathrm{O}_{2}\right)$ was generated in a $95 \% \mathrm{~N}_{2}, 5 \% \mathrm{CO}_{2}$ incubator (Thermo). MCF-7(S) were generated by resuspending $1 \times 10^{4}$ MCF-7 cells in complete RPMI 1640 medium and plated in $3-\mathrm{cm}^{2}$ low attachment plates (Corning). Hypoxia-resistant MCF-7-derived HYPO-7 cells have been previously described (60).

Hypoxia-induced cell death. Cell death was induced by exposing MCF-7 cells, HYPO-7 cells, and MS to DFX at concentrations of 100, 600, and $50 \mu \mathrm{M}$, respectively, following previously described protocols $(26,60)$. Cell death in MS was evaluated by Trypan blue staining of single cells obtained from the trypsin disaggregation of MS, as previously described (26).
Transient and stable RNA interference. Double-strand RNA oligonucleotides (siRNA) directed against IL-6 (Stealth validated RNAi DuoPaks), CA-IX, and Jagged-1 (Stealth select 3 RNAi set) mRNA, and appropriate control scrambled siRNAs, were purchased from Invitrogen. siRNAs were transfected to adherent MCF-7 cells $\left(10^{5}\right.$ cells in a $3-\mathrm{cm}^{2}$ well $)$ at a concentration of $1 \mu \mathrm{g} /$ well using Lipofectamine 2000 (Invitrogen). siRNA transfection in MS and MCF-7(S) was performed by mixing $1 \mu \mathrm{g}$ siRNA with In vitro JET-PEI reagent (Poly plus Transfection). Notch-3 specific shRNA was obtained by cloning an oligonucleotide consisting of a BgIII site, a 21- to 22-nt sense sequence (GATCCCCCTCCCCTCACCACCTAATAAAT/TCAAGAGATTTATTAGGTGGTGAGGGGAGTTTTTGGAAC), a short spacer (TTCAAGAGA), a 21- to 22-nt antisense sequence (TCGAGTTCCAAAAACTCCCCTCACCACCTAATAAATCTCTTGAATTTATTAGGTGGTGAGGGGAGGGG), 5 thymidines (a stop signal for RNA polymerase III), and a XhoI site into the pSuper-Puro expression retroviral vector (OligoEngine). The same vector encoding for a shRNA that does not match to any human known transcript (5'-GATCCCCAATATCCTTGGACACAAGTTGTTCAAGAGACAACTTGTGTCCAAGGATATTTTTTTGGAAC-3') was used as control for Notch-3 shRNA. Retroviral gene transfer was performed as follows: Phoenix cells (kindly provided by G. Nolan, Stanford University, Stanford, California, USA) were grown at $60 \%$ confluence and were transfected overnight with $30 \mu \mathrm{g}$ pSuper-Puro vector encoding a Notch-3 or control shRNA using Lipofectamine 2000 (Invitrogen). Two days after transfection, the medium containing newly packaged retrovirus was collected and filtered through a $0.45-\mu \mathrm{m}$ pore size filter. After supplementation with $4 \mu \mathrm{g} / \mathrm{ml}$ polybrene (Sigma-Aldrich), the augmented medium was applied to MCF-7 cells at 50\% confluence for 24 hours. Successfully infected cells were selected by culturing the cells in presence of $2 \mu \mathrm{g} / \mathrm{ml}$ puromycin for 2 weeks.

Expression vectors. The active form of Notch-3, pNICD-3, was cloned by PCR with forward (TCTTGCTGCTGGTCATTCTC) and reverse (GGCCCCCAAGATCTAAGAAC) primers using Herculase Taq polymerase (Stratagene). The PCR product was inserted into pcDNA3.1/V5-His Topo TA Expression Vector (Invitrogen).

RT-PCR analysis. Total RNA was extracted from cultured cells, MS, and archival tissues ( $n=19$; Table 1 , samples $1-3$, and Table 2$)$ that had been frozen in liquid nitrogen at the time of surgical resection using the RNAextracting reagent TRIzOL (Invitrogen). Primers used in the RT-PCRs were as follows: IL-6, annealing temperature $62^{\circ} \mathrm{C}$, amplicon length $170 \mathrm{bp}$, forward 5'-GAGAAAGGAGACATGTAACAAGAGT-3', reverse 5'-GCGCAGAATGAGATGAGTTGT-3'; Notch-3, annealing temperature $62^{\circ} \mathrm{C}$, amplicon length $93 \mathrm{bp}$, forward $5^{\prime}$-TCAGGCTCTCACCCTTGG-3', reverse 5'-AGTCACTGGCACGGTTGTAG-3'; CA-IX, annealing temperature $61^{\circ} \mathrm{C}$, amplicon length $589 \mathrm{bp}$, forward 5'-CAGGGACAAAGAAGGGGATGAC-3', reverse 5'-TTGGAAGTAGCGGCTGAAGTCA-3'; Bmi-1, annealing temperature $62^{\circ} \mathrm{C}$, amplicon length $220 \mathrm{bp}$, forward $5^{\prime}$ GGAGACCAGCAAGTATTGTCCTTTTG-3', reverse 5'-CATTGCTGGGCATCGTAAG-3'; Jagged-1, annealing temperature $62^{\circ} \mathrm{C}$, amplicon length $170 \mathrm{bp}$, forward $5^{\prime}$-TCGCTGTATCTGTCCACCTG-3', reverse 5'-AGTCACTGGCACGGTTGTAG-3'; CK-5, annealing temperature $55^{\circ} \mathrm{C}$, amplicon length $409 \mathrm{bp}$, forward $5^{\prime}$ TAGGTGGTGGGCTCAGTGTGG-3', reverse 5'-ACTTTGGGTTCTCGTGTCAGC-3'; CD133, annealing temperature $60^{\circ} \mathrm{C}$, amplicon length $286 \mathrm{bp}$, forward 5'-CTGGGGCTGCTGTTTATTATTCTG-3', reverse 5'-ACGCCTTGTCCTTGGTAGTGTTG-3'; BCRP-1, annealing temperature $62^{\circ} \mathrm{C}$, amplicon length $400 \mathrm{bp}$, forward $5^{\prime}$-GTTTATCCGTGGTGTGTCTGG-3', reverse 5'-CTGAGCTATAGAGGCCTGGG-3'; CD44, annealing temperature $62^{\circ} \mathrm{C}$, amplicon length $300 \mathrm{bp}$, forward 5'-CAGCAACCCTACTGATGATGACG-3', reverse 5'-GCCAAGAGGGATGCCAAGATGA-3'; Oct-4, annealing temperature $62^{\circ} \mathrm{C}$, amplicon length $169 \mathrm{bp}$, forward $5^{\prime}$-CTTGCTGCAGAAGTGGGTGGAGGAA-3', reverse 5'-TGCCCGAAACCCACACTGCAG-3'; 
$\beta_{2} \mu$, annealing temperature $58^{\circ} \mathrm{C}$, amplicon length $180 \mathrm{bp}$, forward $5^{\prime}$ ACCCCCACTGAAAAAGATGA-3', reverse 5'-ATCTTCAAACCTCCATGA-3'. PCR primers and reagents were purchased from Invitrogen.

Boyden chamber invasion assay. Cell invasion into Matrigel was assessed by using Boyden chambers (New Technologies Group), containing a poly-vinyl-pyrrolidone free polycarbonate filters with $8-\mu \mathrm{m}$ pores, coated with $15 \mu \mathrm{g}$ Matrigel (Sigma-Aldrich). Cells $\left(1 \times 10^{5}\right)$ and trypsin disaggregated MS $\left(1-5 \times 10^{2}\right.$ cells) were seeded in the upper chamber in serumfree medium in the presence or absence of IL- $6(10 \mathrm{ng} / \mathrm{ml})$ or anti-IL-6 $(1.5 \mu \mathrm{g} / \mathrm{ml})$; complete medium was placed in the lower compartment as chemoattractant. In several experiments cells and MS were also transfected with appropriate siRNA for 48 hours and then collected, resuspended in $500 \mu \mathrm{l}$ in the presence of IL-6 $(10 \mathrm{ng} / \mathrm{ml})$ or anti-IL-6 $(1.5 \mu \mathrm{g} / \mathrm{ml})$, and seeded in the upper chamber for 24 hours at $37^{\circ} \mathrm{C}$ in a $5 \% \mathrm{CO}_{2}$ atmosphere. At the end of incubation, noninvading cells were removed from the upper surface of the filters, and invading cells in the lower surface were fixed in ice-cold methanol, stained with Toluidine Blue staining (Sigma-Aldrich), and scored as the mean number of invaded cells per 5 random optical fields, in 3 independent experiments, at $\times 20$ magnification.

Gelatin zymography. MMP-2 activity was determined by gelatin zymography. Briefly, proteins of collected media were precipitated with 1:4 (vol/vol) ice-cold methanol overnight at $-20^{\circ} \mathrm{C}$, solubilized with sample buffer without mercaptoethanol (1 M Tris-HCl, pH 6.8, 2\% SDS, 10\% glycerol) and loaded into $10 \%$ SDS-polyacrylamide gel containing $1 \mathrm{mg} / \mathrm{ml}$ gelatine (Sigma-Aldrich). Gel was then incubated in a developing buffer $\left(100 \mathrm{mM}\right.$ Tris- $\mathrm{HCl}, 10 \mathrm{mM} \mathrm{CaCl}{ }_{2}$, $20 \mathrm{mM} \mathrm{NaCl}, \mathrm{pH} 7.6$ ) overnight at $37^{\circ} \mathrm{C}$, stained for 2 hours with $1 \%$ Coomassie Brilliant Blue R-250, and finally destained in a solution containing $10 \%$ acetic acid and $40 \%$ methanol. MMP-2 proteolytic activity was quantified using a semiautomated image analysis (GelDoc; BioRad Laboratories).
Western blot. Cell lysates were prepared, run, and blotted using standard methodologies, and probed specific antibodies: rabbit polyclonal anti-Notch-3 (clone M-134; Santa Cruz), mouse mAbs anti-ERK and anti-phosphorylated ERK (Cell Signalling), $\beta$-Actin (Sigma-Aldrich), and CA-IX (clone M-75).

Statistics. Continuous variables (percentages of dead cells, number of invading cells in Boyden Chamber assays) were analyzed by ANOVA (unequal variance assumed). Post-hoc test (unequal variance assumed) was used to compare more than 2 groups. Non-normally distributed variables (RT-PCR normalized values of mRNA level) were analyzed by 2 -sample nonparametric test (Mann-Whitney). Categorical variables (MS and spheroid size distribution) were analyzed by Monte Carlo $\chi^{2}$ test. All the tests were implemented in SPSS 10.1 Package (SPSS). A $P$ value less than 0.05 was considered significant.

\section{Acknowledgments}

This work has been supported by University of Bologna RFO funds-ex 60\%, Cornelia Pallotti and Roberto Pallotti Foundation to M. Bonafè, and FIRB project RBNE03KZRJ to P. Chieco. We also thank Fondazione Cassa di Risparmio in Bologna for supporting the Center for Applied Biomedical Research.

Received for publication April 27, 2007, and accepted in revised form September 12, 2007.

Address correspondence to: Massimiliano Bonafè, Department of Experimental Pathology, Via S. Giacomo 12, 40126, Bologna, Italy. Phone: 39-051-636-4009; Fax: 39-051-636-3902; E-mail: massimiliano.bonafe@unibo.it.
1. Hodge, D.R., Hurt, E.M., and Farrar, W.L. 2005. The role of IL- 6 and STAT3 in inflammation and cancer Eur. J. Cancer. 41:2502-2512.

2. Rose-John, S., Scheller, J., Elson, G., and Jones, S.A. 2006. Interleukin-6 biology is coordinated by membrane-bound and soluble receptors:role in inflammation and cancer. J. Leukoc. Biol. 80:227-236.

3. Knupfer, H., and Preiss, R. 2007. Significance of interleukin-6 (IL-6) in breast cancer (review). Breast Cancer Res. Treat. 102:129-135.

4. Bachelot, T., et al. 2003. Prognostic value of serum levels of interleukin 6 and of serum and plasma levels of vascular endothelial growth factor in hormone-refractory metastatic breast cancer patients. Br. J. Cancer. 88:1721-1726.

5. Zhang, G.J., and Adachi, I. 1999. Serum interleukin-6 levels correlate to tumor progression and prognosis in metastatic breast carcinoma. Anticancer Res. 19:1427-1432.

6. Knupfer, H., et al. 2004. CYP2C and IL-6 expression in breast cancer. Breast. 13:28-34.

7. Asgeirsson, K.S., Olafsdottir, K., Jonasson, J.G., and Ogmundsdottir, H.M. 1998. The effects of IL-6 on cell adhesion and E-cadherin expression in breast cancer cells. Cytokine. 10:720-728.

8. Sehgal, P.B., and Tamm, I. 1991. Interleukin-6 enhances motility of breast carcinoma cells. EXS. 59:178-193.

9. Yeh, H.H., Lai, W.W., Chen, H.H., Liu, H.S., and Su, W.C. 2006. Autocrine IL-6-induced Stat3 activation contributes to the pathogenesis of lung adenocarcinoma and malignant pleural effusion. Oncogene. 25:4300-4309.

10. Conze, D., et al. 2001. Autocrine production of interleukin 6 causes multidrug resistance in breast cancer cells. Cancer Res. 61:8851-8858.

11. Selander, K.S., et al. 2004. Inhibition of gp130 signaling in breast cancer blocks constitutive activation of Stat 3 and inhibits in vivo malignancy. Can- cer Res. 64:6924-6933.

12. Trikha, M., Corringham, R., Klein, B., and Rossi, J.F. 2003. Targeted anti-interleukin- 6 monoclonal antibody therapy for cancer: a review of the rationale and clinical evidence. Clin. Cancer Res. 9:4653-4665.

13. Dontu, G., Liu, S., and Wicha, M.S. 2005. Stem cells in mammary development and carcinogenesis: implications for prevention and treatment. Stem Cell Rev. 1:207-213.

14. Fillmore, C., and Kuperwasser, C. 2007. Human breast cancer stem cell markers CD44 and CD24: enriching for cells with functional properties in mice or in man? Breast Cancer Res. 9:303.

15. Reya, T., Morrison, S.J., Clarke, M.F., and Weissman, I.L. 2001. Stem cells, cancer, and cancer stem cells. Nature. 414:105-111.

16. Sheridan, C., et al. 2006. CD44+/CD24- breast cancer cells exhibit enhanced invasive properties: an early step necessary for metastasis. Breast Cancer Res. 8:R59.

17. Hu, C., et al. 2006. Overexpression of activated murine Notch 1 and Notch 3 in transgenic mice blocks mammary gland development and induces mammary tumors. Am. J. Pathol. 168:973-990.

18. Reedijk, M., et al. 2005. High-level coexpression of JAG1 and NOTCH1 is observed in human breast cancer and is associated with poor overall survival. Cancer Res. 65:8530-8537.

19. Stylianou, S., Clarke, R.B., and Brennan, K. 2006. Aberrant activation of notch signalling in human breast cancer. Cancer Res. 66:1517-1525.

20. Boecker, W., and Buerger, H. 2003. Evidence of progenitor cells of glandular and myoepithelial cell lineages in the human adult female breast epithelium: a new progenitor (adult stem) cell concept. Cell Prolif. 36:73-84

21. Dontu, G., et al. 2003. In vitro propagation and transcriptional profiling of human mammary stem/progenitor cells. Genes Dev. 17:1253-1270.
22. Dontu, G., and Wicha, M.S. 2005. Survival of mammary stem cells in suspension culture: implications for stem cell biology and neoplasia. J. Mammary Gland Biol. Neoplasia. 10:75-86.

23. Liu, S., Dontu, G., and Mantle, I.D. 2006. Hedgehog signaling and Bmi-1 regulate self-renewal of normal and malignant human mammary stem cells. Cancer Res. 66:6063-6071.

24. Dontu, G., et al. 2004. Role of Notch signaling in cell-fate determination of human mammary stem/ progenitor cells. Breast Cancer Res. 6:R605-R615.

25. Farnie, G., et al. 2007. Novel Cell Culture Technique for Primary Ductal Carcinoma In Situ: Role of Notch and Epidermal Growth Factor Receptor Signaling Pathways. J. Natl. Cancer Inst. 99:616-627.

26. Sansone, P., et al. 2007. p66Shc/Notch-3 interplay controls self-renewal and hypoxia survival in human stem/progenitor cells of the mammary gland expanded in vitro as mammospheres. Stem Cells. 25:807-815.

27. Ponti, D., et al. 2005. Isolation and in vitro propagation of tumorigenic breast cancer cells with stem/ progenitor cell properties. Cancer Res. 65:5506-5511.

28. Al-Hajj, M., Wicha, M.S., Benito-Hernandez, A., Morrison, S.J., and Clarke, M.F. 2003. Prospective identification of tumorigenic breast cancer cells. Proc. Natl. Acad. Sci. U. S. A. 100:3983-3988.

29. Li, C., et al. 2007. Identification of pancreatic cancer stem cells. Cancer Res. 67:1030-1037.

30. Bonafe, M., et al. 2001. A gender--dependent genetic predisposition to produce high levels of IL- 6 is detrimental for longevity. Eur. J. Immunol. 31:2357-2361.

31. Singh, S.K., et al. 2004. Identification of human brain tumour initiating cells. Nature. 432:396-401.

32. O'Brien, C.A., Pollett, A., Gallinger, S., and Dick, J.E. 2007. A human colon cancer cell capable of initiating tumour growth in immunodeficient mice. Nature. 445:106-110.

33. Ho, M.M., Ng, A.V., Lam, S., and Hung, J.Y. 2007. 
Side population in human lung cancer cell lines and tumors is enriched with stem-like cancer cells. Cancer Res. 67:4827-4833.

34. Nielsen, T.O., et al. 2004. Immunohistochemical and clinical characterization of the basal-like subtype of invasive breast carcinoma. Clin. Cancer Res. 10:5367-5374.

35. Bertheau, P., et al. 2007. Exquisite sensitivity of TP53 mutant and basal breast cancers to a dosedense epirubicin-cyclophosphamide regimen. PLoS Med. 4:e90.

36. Bertucci, F., Cervera, N., and Birnbaum, D. 2007. A gene signature in breast cancer. N. Engl. J. Med. 356:1887-1888.

37. Charafe-Jauffret, E., et al. 2006. Gene expression profiling of breast cell lines identifies potential new basal markers. Oncogene. 25:2273-2284.

38. Phillips, T.M., McBride, W.H., and Pajonk, F. 2006 The response of CD24(-/low)/CD44+ breast cancer-initiating cells to radiation. J. Natl. Cancer Inst. 98:1777-1785

39. Kopacek, J., et al. 2005. MAPK pathway contributes to density- and hypoxia-induced expression of the tumor-associated carbonic anhydrase IX. Biochim. Biophys. Acta. 1729:41-49.

40. Prince, M.E., et al. 2007. Identification of a subpopulation of cells with cancer stem cell properties inhead and neck squamous cell carcinoma. Proc. Natl. Acad. Sci. U. S. A. 104:973-978.

41. Liu, R., et al. 2007. The prognostic role of a gene signature from tumorigenic breast-cancer cells. N. Engl. J. Med. 356:217-226.

42. Haruki, N., et al. 2005. Dominant-negative Notch3 receptor inhibits mitogen-activated protein kinase pathway and the growth of human lung cancers.
Cancer Res. 65:3555-3561.

43. Talora, C., et al. 2003. Pre-TCR-triggered ERK signalling-dependent downregulation of E2A activity in Notch3-induced T-cell lymphoma. EMBO Rep. 4:1067-1072.

44. Svastova, E., et al. 2004. Hypoxia activates the capacity of tumor-associated carbonic anhydrase IX to acidify extracellular pH. FEBS Lett. 577:439-445.

45. Rofstad, E.K., Mathiesen, B., Kindem, K., and Galappathi, K. 2006. Acidic extracellular $\mathrm{pH}$ promotes experimental metastasis of human melanoma cells in athymic nude mice. Cancer Res. 66:6699-6707.

46. Duffy, M.J., Maguire, T.M., Hill, A., McDermott, E., and O'Higgins, N. 2000. Metalloproteinases: role in breast carcinogenesis, invasion and metastasis. Breast Cancer Res. 2:252-257.

47. Hussain, S.A., et al. 2007. Hypoxia-regulated carbonic anhydrase IX expression is associated with poor survival in patients with invasive breast cancer. Br. J. Cancer. 96:104-109.

48. Brennan, D.J., et al. 2006. CA-IX is an independent prognostic marker in premenopausal breast cancer patients with one to three positive lymph nodes and a putative marker of radiation resistance. Clin. Cancer Res. 12:6421-6431.

49. Makretsov, N.A., et al. 2004. Hierarchical clustering analysis of tissue microarray immunostaining data identifies prognostically significant groups of breast carcinoma. Clin. Cancer Res. 10:6143-6151.

50. Garcia, S., et al. 2007. Poor prognosis in breast carcinomas correlates with increased expression of targetable CD146 and c-Met and with proteomic basal-like phenotype. Hum. Pathol. 38:830-841.

51. Coussens, L.M., and Werb, Z. 2002. Inflammation and cancer. Nature. 420:860-867.
52. Petersen, O.W., Ronnov-Jessen, L., Howlett, A.R., and Bissel, M.J. 1992. Interaction with basement membrane serves to rapidly distinguish growth and differentiation pattern of normal and malignant human breast epithelial cells. Proc. Natl. Acad. Sci.U.S. A. 89:9064-9068.

53. Finak, G., et al. 2006. Gene expression signatures of morphologically normal breast tissue identify basal-like tumors. Breast Cancer Res. 8:R58.

54. Rao, V.P., et al. 2006. Proinflammatory CD4+ CD45RB(hi) lymphocytes promote mammary and intestinal carcinogenesis in $\mathrm{Apc}(\mathrm{Min} /+)$ mice. Cancer Res. 66:57-61.

55. Lin, E.Y., et al. 2006. Macrophages regulate the angiogenic switch in a mouse model of breast cancer. Cancer Res. 66:11238-11246.

56. Rao, V.P., Poutahidis, T., Fox, J.G., and Erdman, S.E. 2007. Breast cancer: should gastrointestinal bacteria be on our radar screen? Cancer Res. 67:847-850.

57. Balducci, L. 2003. Geriatric oncology. Crit. Rev. Oncol. Hematol. 46:211-220.

58. World Health Organization. 2003. World Health Organization classification of tumours. In Pathology and genetics of tumour of the breast and female genital organs. F.A. Tavassoli and P. Devilee, editors. IARC Press. Lyon, France. 432 pp.

59. Elston, C.W., and Ellis, I.O. 1991. Pathological prognostic factors in breast cancer. I. The value of histological grade in breast cancer: experience from a large study with long-term follow-up. Histopathology. 19:403-410.

60. Sansone, P., et al. 2007. The p53 codon 72 proline allele is endowed with enhanced cell-death inducing potential in cancer cells exposed to hypoxia. $\mathrm{Br}$. J. Cancer. 96:1302-1308. 